\title{
SOBRE BRUJOS Y LIK'ICHIRIS: LA CREACIÓN CULTURAL DEL HORROR
}

\section{ON WIZARDS AND LIK'ICHIRIS: THE CULTURAL CREATION OF HORROR}

\author{
Gabriel Martínez Soto-Agullar*
}

Este artículo fue originalmente publicado en 1998 en una colección que reunía los distintos trabajos de un equipo de investigación sobre justicia comunitaria, convocado por el Ministerio de Justicia y Derechos Humanos, con la colaboración del Banco Mundial 1988, en La Paz, Bolivia. Este trabajo correspondió entonces al volumen número siete de dicha colección que más tarde sirvió como uno de los fundamentos para las leyes sobre justicia comunitaria de la actual constitución de Bolivia. Desgraciadamente la colección quedó, por motivos políticos, almacenada, sin distribución y sin haber tenido el impacto que merecía desde hace más de quince años. En sus primeras líneas Gabriel Martínez señalaba que el objetivo de su escrito no era otro que ofrecer a los lectores, imberbes y avezados -añadimos nosotros-, una primera entrada al estudio de los brujos y kharisiris, personajes a través de los cuales se puede analizar la justicia comunitaria andina en conflictos de carácter sobrenatural.

Palabras clave: justicia comunitaria, brujos, lik'ichiris, kharisiris, Bolivia, etnografía

This article was originally published in 1998 in La Paz, Bolivia, as part of a collection of papers on community justice by a research team organized by the Ministry of Justice and Human Rights with the collaboration of the World Bank 1988. This document was included in vol. seven, which later became one of the basis for the community justice laws codified in the Constitution of Bolivia. Unfortunately, due to political reasons, the collection had not been distributed, and for more than 15 years it did not have the impact it deserved. In the first lines of the collection, Gabriel Martinez pointed out that the goal of his text was to offer to the readers-both novices and experts, we add-an introduction to the study of witches and kharisiris, personalities by which it is possible to analyze the Andean community justice on conflicts regarding supernatural issues.

Key words: community justice, witches, lik'ichiris, kharisiris, Bolivia, ethnography

\section{INTRODUCCIÓN}

El estudio que el lector tiene en sus manos ahora no pretende ser más que una primerísima aproximación a los temas de brujos y kharisiris (degolladores), como los personajes donde nos pareció más probable encontrar expresiones de intervención de la justicia comunitaria andina, en conflictos de carácter sobrenatural.

Los directores de la investigación general sobre derecho consuetudinario indígena no quisieron dejar fuera de una visión inicial uno de los campos donde al parecer mejor se expresan el espíritu, los criterios y las prácticas de la justicia tradicional. También porque es uno de los campos donde mejor se manifiesta la complejidad del pensamiento mítico indígena y, por ello, debería permitirnos acceder a una mayor comprensión de la riqueza

* Gabriel Martínez Soto-Aguilar, antropólogo chileno radicado en Bolivia, falleció a comienzos del año 2000. La reedición de este artículo estuvo a cargo de Paula Martínez Sagredo, email: pmartinezsagredo@gmail.com 
de las culturas del país. Contrariamente, es también el ámbito donde se siguen manifestando los prejuicios racistas antiindígenas de muchas personas que gobiernan esta nación. En verdad, los estudios sobre magia/brujería indígenas tienen el valor estratégico de tocar uno de los problemas cruciales de la identidad boliviana: el problema de "lo indígena y la interculturalidad". A estas implicaciones se agregaban también otras dificultades: el lector culto sabe que los estudios de magia, brujería y otras expresiones del pensamiento mítico constituyen uno de los campos más elusivos de la antropología moderna. Y puede suponer también que el estado actual de estos estudios, aquí en el país, presenta grandes lagunas y vacíos. Finalmente, las fuertes limitaciones de tiempo constituyeron quizás el mayor de los obstáculos: cinco meses para investigar cómo para dar forma final a un trabajo, son absolutamente insuficientes para abordar este tipo de temas donde incluso el trabajo de campo no puede ser directo.

Esto explica las limitaciones de este informe. Me vi, pues, en la necesidad de circunscribir rigurosamente los temas y los materiales de trabajo. Tuve, también, que hacer una primera elección sobre los grupos étnicos que podía encarar, y decidí concentrar mi trabajo, en general, en los grupos indígenas andinos (quechuas y aymaras), que conozco mejor, dejando fuera los grupos amazónicos y de las tierras bajas, para una posterior y más holgada oportunidad.

Una segunda serie de elecciones fue también necesaria: el tema general de mi investigación era el estudio de casos donde se viera el comportamiento de las comunidades (dirigentes, gente considerada sabia, comunarios), administrando justicia según la costumbre, en conflictos donde actores supuestamente malignos hacían uso de instrumentos, creencias, prácticas, complejos de pensamiento, de carácter mágico y/o mitológico, contra determinadas personas. Por eso se los llamó "conflictos de carácter sobrenatural". Pero eso significaba investigar sobre una enorme variedad de casos, de una enorme cantidad de sacerdotes indígenas, especialistas en diversidad de intervenciones, técnicas y recursos psicológicos, psicosomáticos y médicos. Eso implicaba, prácticamente, investigar toda la magia, el pensamiento mítico, la mitología y el arte de curar indígenas. Era obviamente excesivo, imposible.

De manera que, como estrategia, decidí abordar solamente los casos de brujería, y dentro de esta, los casos de los "brujos malignos": lo más probable era encontrar aquí "conflictos de origen sobrenatural". He dejado por tanto afuera a los llamados yatiris o yachaj (hombres sabios) que generalmente saben curar, a quienes también algunos tratan de "brujos". Y también he dejado afuera a otros numerosos especialistas, de distintas designaciones (ch'amakanis, jampiris, aysiris, etc.; a los cuales me refiero en nota aparte), en cuyos desempeños no siempre es fácil separar la buena intención de la malignidad.

Decidí también tomar casos de lik'ichiris, los "saca grasa" o "degolladores". Aquí definitivamente encontramos los conflictos de "carácter sobrenatural" y se trata de casos relativamente documentados. Es este, justamente, un punto en el que, por lo general, desde el ámbito urbano, se manifiesta una más absoluta incomprensión de la motivación indígena. La temática se centró, de este modo, solamente en brujos y lik'ichiris.

Otra determinación importante fue dejar fuera de este estudio un análisis detallado de todo lo que constituyen las prácticas mismas de la brujería: los ingredientes, parafernalia, rituales, sistemas de adivinación (en coca, naipes y otros), gestualidad, invocaciones, figuras mitológicas, etc.

Muchas otras cosas no han podido tampoco ser tomadas en cuenta, por las razones antes señaladas. Este trabajo, ya se habrá advertido, no es un "tratado de magia y mítica andina". Como se dijo más atrás es un mero acercamiento a esta clase de temas -por lo general muy poco conocidos y siempre mal comprendidos- que deberán esperar una segunda fase para ser adecuadamente resueltos por equipos interdisciplinarios, en relación con los problemas de la justicia comunitaria. ${ }^{1}$

\section{APROXIMACIONES A LA BRUJERÍA ANDINA}

Cuando empecé a trabajar en el análisis del tema de la brujería andina, el material recolectado se me dio, muy pronto, como organizado en dos órdenes de realizaciones distintas: uno, los relatos de brujería, otro, los hechos de brujería. Los relatos de brujería constituían todos los cuentos, las historias, los saberes sobre brujería, que la gente de las comunidades narra. Se da por entendido que todas estas narraciones relatan "hechos de brujería" auténticos, sucesos realmente ocurridos en una comunidad o en otra, en una época o en otra, protagonizados por tal o cual brujo o bruja, victimando a tales o cuales personas, que existieron o aún existen. El relato incluye o no, según el caso, reacciones de la gente contra el brujo, castigos impuestos por la comunidad, alguna vez ajusticiamiento del 
brujo. El relato de brujería se plantea, a sí mismo, como un registro oral de sucesos ocurridos y con el testimonio fidedigno de alguien conocido. Por su parte, los hechos de brujería eran, en cambio, lo que el nombre indica: los acontecimientos mismos, ocurridos en la realidad física espacio-temporal.

Es posible, teóricamente, que en determinados casos de esta naturaleza sucedidos de alguna manera tangible y concreta, tengan su relato, o sus relatos, y que ellos se narren con cierta objetividad; pero no estoy seguro de que siempre ocurra así. Más bien estoy inclinado a creer que existe una brecha entre los relatos y los hechos mismos que los originan. Y que, en general, los relatos de brujería no narran hechos "verdaderamente" acaecidos. Los hechos de brujería cuando existen, y aun los más relevantes y conocidos, no parecen estar, en ninguna parte, relatados con cierta confiable fidelidad. Existe, en cambio, una masa enorme de producciones orales sobre este tema, en cada comunidad y, a veces, compartidos por las comunidades de una región: ellos expresan el pensamiento indígena sobre la brujería, el conocimiento que se tiene sobre las prácticas, las operaciones y los procedimientos de brujos, antibrujos y víctimas: el área rural en la región andina está llena de esta clase de textos que se confunden, muchas veces, con la narrativa oral. Cada persona tiene un repertorio profuso de "relatos sobre brujos". Es prácticamente de aquí, de este material, de donde salen todos nuestros conocimientos sobre la brujería andina. En cambio, no tenemos ningún registro específico de los hechos mismos: ni la descripción etnográfica precisa y objetiva de un observador imparcial, ni la crónica periodística testimonial que pueda ser constatable, ni por último el relato aparentemente fidedigno de un acta policial o judicial. De los relatos de brujería -por razones estructurales- no podemos tener ninguna evidencia de que tal o cual hecho de brujería efectivamente haya ocurrido, y cómo. Al analizarlos en primer lugar, estamos prestando atención a lo que se dice, no a lo que se hace, para desentrañar de qué manera la cultura aborda y piensa el tema.

\section{LOS RELATOS DE BRUJERÍA. SU NATURALEZA}

\section{Localización espacio-temporal y actoral (con los actores)}

Lo que me hizo advertir que los relatos de brujería no eran crónicas o registros fidedignos de hechos ciertos, fue el advertir que en ellos se mezclaban, entreveradamente, datos muy precisos de la realidad del tiempo, lugar y personajes de los acontecimientos narrados, con "motivos" ya hechos del relato oral sobre brujos, o con figuras fantásticas del universo mágico andino, que surgen también en otros contextos y otras imágenes típicas de la brujería.

En efecto, la mayoría de este tipo de relatos hace uso de una serie de recursos para localizar, con mucha precisión en el tiempo y en el espacio, los hechos ocurridos. La referencia a ciertas personas que existieron en la realidad, que fueron testigos o intervinieron en los hechos que se van a relatar, contribuye eficazmente a localizar en una "realidad muy real" a los hechos de brujería, como ocurre, por ejemplo, con el texto de la siguiente entrevista:

Una vez había. Era la época de la hacienda. Yo era como él [señala a un chico de 11 años que asiste a la entrevista]. Esto pasó en Quila Quila. Mucho antes estaba el señor... [trata de acordarse del nombre] Ahí arriba hay un Juan Mayorga. ${ }^{2}$ Vive aquí, aquí en la calle La Paz. Él contó... ¡No, contó su hermano! Él estaba de corregidor en esa temporada. En Quila Quila, donde estoy diciendo, solía haber fiestas para septiembre: sabíamos estar en la hacienda, en una de esas fiestas. Una vez un llamero ${ }^{3}$ se acercó a la fiesta donde se repartía comida y bebida. La gente de Quila Quila es mala, no sabe invitar a los forasteros. El llamero al acercarse se antojó la comida y la bebida, pero no le invitaron nada. Después se fue muy disgustado hacia las alturas, levantó una jarana ${ }^{4}$ muy cerca de un manantial; en esa loma se acostumbraba a levantar las jaranas. Al llegar a su jarana ¿qué hizo? ¡Uh, embrujó a la población! Al día siguiente cayó una granizada que parecían huevos de gallina. Quila Quila estaba blanca por el granizo, aún no habían sembradíos, los duraznos estaban en flor, aquí produce mucho durazno.

En este relato no solo se ubica con precisión el lugar del acontecimiento -en la comunidad de Quila Quila- y la época -época de la hacienda (antes de la Reforma Agraria de 1953), en las fiestas de septiembre-, sino que también algún actor del momento: el subprefecto Mayorga. Dejando de lado lo fantástico del acontecimiento, quisiera destacar que el relato hace uso de un motivo andino, muy antiguo, que viene desde la época prehispánica: el hombre poderoso (generalmente un dios, en este caso un brujo), que parece pobre, que se acerca a donde hay una fiesta y nadie le convida nada, lo que precipita la venganza. Comparemos el relato de Quila Quila con uno del siglo xvII:

El dios Pariacaca se acerca un día a una comunidad llamada Huayquihusa. "En esa época, los miembros de esa comunidad celebraban una fiesta importante con una gran borrachera. Mientras bebían, llegó Pariacaca. Se sentó a un lado como suelen hacer los pobres. Ninguno de los Huayquihusa le sirvió de beber. Pasó el día entero. Finalmente una mujer, que también era miembro de esa 
comunidad, exclamó: “Añani! ¿Cómo es posible que no le hayan convidado nada a este pobrecito?”. Le ofrece chicha y él, agradeciéndole, la conmina a dejar la comunidad en cinco días, ya que algo terrible va a ocurrir. "Mucho me ha enojado esta gente". [...] Entonces, cinco días más tarde, la mujer, sus hijos y hermanos, se retiraron de aquel lugar. Los demás miembros de la comunidad seguían bebiendo tranquilamente. Pariacaca subió al cerro... En ese cerro... Pariacaca se transformó en tempestad de lluvia. Bajo la forma de granizo amarillo y rojo, arrastró a toda aquella gente... (Taylor 1987: 123-125).

La similitud de los motivos es asombrosa: mezquindad (no reciprocidad andina), desconocimiento de los poderes de quien aparece como humilde, subida al cerro para castigar y, luego, el granizo que asuela a la población. Esta similitud, no casual, está señalando que el hecho ocurrido en Quila Quila, al ser narrado, entra en formas de construcción tradicional de un relato de embrujo, que lo acercan al relato mítico y lo alejan de una crónica normal.

Pero, al mismo tiempo, la precisión de los lugares y la mención a nombres de personas que realmente existieron el prefecto Mayorga, por ejemplo -confieren al relato su efecto sobre el oyente "de haber ocurrido así", de ser un hecho real. Esta precisión del lugar y de los nombres de los protagonistas, brujo y víctima, es común a muchos relatos y constituye una suerte de garantía de credibilidad. Por ejemplo, otro narrador cuenta que "Había una bruja llamada Felipa, su esposo se llamaba Lino, su hija mayor se llamaba Fortunata; eran tres sus hijas. Ellos vivían en el ranchito de Pitukuno, en el sector de Talina; vivían al lado de la casa de mis tíos Bartolomé y Dámasa, por esta razón la conocíamos bien a Francisca".

De este modo el narrador se ubica él mismo dentro de la historia ¿̨cómo no creerle? Más adelante, en el mismo relato, refiriéndose a la intervención de un curandero, añade que "hemos recurrido a un curandero. El curandero se llamaba Marcelo Ramos, tenía el mismo nombre de mi padre. Este señor vivía en el pueblito de Palca de Flores, que se encuentra entre los pueblitos de Vitichi y Vilcaya, sobre el camino carretero Potosí-Villazón". Y casi extremando el recurso de localización, termina diciendo:

Así nos hizo esa bruja Felipa. Deben vivir todavía sus hijos, porque este hecho data más o menos del año 1930, en la comunidad de Liriyuj y Pitukuno, que dependían del ayllu Pasla; actualmente más o menos existen en las dos comunidades unas nueve familias. A estos ranchitos no llega el camino carretero. Toda la población se dedica a la cerámica, es su medio de sustento, viven en unos cerros muy accidentales [sic].

\section{Figuras ya hechas}

No cabe duda que estas precisiones de tiempo, lugar y personas le prestan al relato de brujería una gran "verosimilitud": nadie duda de que los hechos que se van a narrar o se están narrando, "ocurrieron realmente". Producen un gran efecto de verdad. Pero este efecto de verdad empieza a deshacerse pronto al introducir el relator nuevos componentes o recursos "ya hechos", ya preparados y atesorados en la cultura andina. Algunos de estos recursos son, sin embargo, "motivos" sutiles, como, por ejemplo, el motivo de un comportamiento precoz y extraño de las personas que de adultos serán considerados como brujos. Así por ejemplo, un narrador cuenta:

Aquí en la comunidad de Rufo dice que había un niño... Desde muy chiquito, hasta llegar a ser un joven, se perdía entre las rocas gritando. Se salía de su casa corriendo, en las tardes, y se perdía entre las rocas, gritando; de las rocas solo salía a las doce de la noche. Gritando dicen que se perdía, desaparecía en la cueva. Después que llegaba, después de un rato, dice que llegaba sano... El niño ya era joven; esa comadre aún vive, ella sabe contar de esa manera. Dice que llegaba sano, y tranquilo solía estar.

Una conducta insólita así, en un niño, ya denuncia a un ser extraño y anormal. A ella se van agregando otros rasgos:

El hijo de su hermano [del hermano del brujo] se casó. Cuando tenía que casarse el hijo de su hermano, dice que no ayudó en los preparativos; debió ser su tío, su tío no ayudó en nada a su sobrino... No ayudó en nada, ni siquiera yendo a buscar leña o trayendo agua, ni ayudando a carnear a los animales, nada. A pesar de ello lo invitaron al matrimonio en Sucre. Cuando llegó a Sucre, no le invitaron ni un poco de rosquetes, ni ají. Tal vez se enojaron, o qué diciendo... "¿Acaso ayudó? Ahora, sin hacer nada, viene a hablar y bailar aquí..." Él se ha debido enojar. Al día siguiente, como ahora, después de salir llegó a la casa del matrimonio de su sobrino; él bailaba con su esposa. Al día siguiente fue al recuento del dinero. Dice que se mezquinó. Esa noche, la novia de su sobrino dice que murió. Se la comió.

Dos veces, según el relato, el brujo mató a novias, como en esta ocasión, y así dice que lo descubrieron como brujo.

Como se comprende, estos temas "ya hechos", como el niño de conducta extraña, o el joven acultural que no sigue la norma de reciprocidad establecida de cooperar en los acontecimientos familiares, son figuras ya conformadas, 
ya establecidas y atesoradas en la cultura, que delatan y tipifican la condición antisocial del brujo, y están listas para ser usadas en cualquier momento. Hay muchas otras como el comportamiento agresivo o pendenciero en las fiestas, por ejemplo.

Es obvio que para el oyente indígena el uso de estos estereotipos refuerza la verosimilitud del hecho de brujería. Pero para el oyente atento de fuera de la cultura evidencian el carácter "construido del relato" y su naturaleza de texto que crea una significación, aunque contenga elementos de una experiencia vivida.

\section{Figuras mágico-míticas}

Esta construcción prácticamente de una fantasía se hace del todo evidente cuando empiezan a aparecer en el relato las figuras temibles del repertorio mágico/mítico de la brujería andina: cabezas y manos voladoras del brujo, sus operaciones contra las víctimas, las relaciones del brujo con el diablo, etc.

Las cabezas voladoras, por ejemplo, son una de las figuras más aterradoras. Como se sabe, los brujos se desprenden de sus cabezas en la noche, y estas van donde el brujo quiere, por lejos que sea, para hacer daño. Sobre estas cabezas voladoras un relator dice:

La bruja, para separar la cabeza de su cuerpo, dicen que utiliza un líquido de yerba, con el cual unta su cuello y automáticamente se corta. También dice que se saca sus ojos y los cambia por los ojos del gato; esos ojos de ella dicen que deja en un plato limpio. Después, al regresar su cabeza vuelve a pegarse a su cuerpo y sus ojos se vuelven a poner. Igualmente de su gato. Por eso dicen que las brujas siempre criaban gatos.

Las manos voladoras. No son solo las cabezas de los brujos las que se desprenden y vuelan para hacer daño: también las manos, una mano. A esto los indígenas andinos llaman (quech.) maki p’itiy, diferenciándolo del desprendimiento de la cabeza, que es uma p'itiy. En palabras de un informante:

Ese maki p'itiy es cuando su mano se desprende del cuerpo; solamente va la mano, ya no la cabeza, también de noche, acompañada de sus animales. De esos brujos que vuela su mano no se puede notar, porque su ropa le tapa el brazo. Pero de los que vuela su cabeza se puede notar claro en su cuello (tienen como un q'aytu $u^{5}$ negro delgado, alrededor). De los brujos que vuela su mano dicen que esos son los finos brujos: esa mano es la que va a poner su hechizada [sic] a la persona que desea para hechizar.

Una persona cuenta de un encuentro suyo con una de estas cabezas voladoras:

Bueno, una vez yo he visto; para contarle más claro, donde vivíamos juntos con mi pap'tutor. Era una noche de luna llena, ha debido ser pasada la media noche [...] La noche era como de día bien claro; como le digo, era luna llena. Haciendo un tremendo ruido [la cabeza voladora] ha venido cerca por su corral con un ruido de animales voladores, como el búho y otros animales de toda clase. Y la cabeza volante también hacía ruido, gritaba como perro, haciendo "Q'aj, q’aj, q'aj, q'aj” [...] Así gritaban los pájaros, también metían harta bulla. La cabeza volante ha sabido ir bajito no más, a la altura de una persona. Después, al día siguiente hemos ido donde su corral de ganados; en ese lugar había piedras grandes, sobre las piedras hemos visto sangre coagulada. No era poco, era harto.

La sangre coagulada. Esta imagen de "la sangre coagulada", en relación con las cabezas voladoras, parece también haberse convertido en uno de estos "motivos" o una de estas figuras mágico-míticas ya establecidas, pues la vemos aparecer en varios relatos como el siguiente: "cuando han llegado los que fueron a ver por qué lloraban las wawas, cuando han llegado, ya no había nada en el lugar, así decía mi mamá. Pero habían encontrado sangre coagulada sobre una piedra plana, así decía mi madre. [...] Ya no había nada cuando habían regresado; como le digo, sangre, sangre es lo que han encontrado".

El muñeco escondido. También algunas de las hechicerías de los brujos a sus víctimas llevan el sello de la acción ya estereotipada, como la fabricación de un muñeco con ropas de la víctima, conteniendo sustancias consideradas maléficas y que solo puede ser descubierto por un antibrujo, es decir, por un yatiri. ${ }^{6}$ No por ello son menos insidiosas. Una cita in extenso de una entrevista hecha nos ayudará a entender mejor todo esto:

Mi papá cuidaba las vacas de mi tío Pablo Choque. Él vivía en el rancho Choque. Una de sus vacas hemos hecho perder. Entonces mi papá ha recurrido a un aysiri ${ }^{7}$ para hacer ver la suerte; el aysiri había consultado a los mallkus y a las "virgines" 8 y los mallkus habían dicho que "el señor ha robado tu vaca". Mi papá, cuando le había dicho así el mallku, después de haber hecho consultar esa noche, al día siguiente se había recogido borracho, y al pasar por la casa de Francisca (una bruja antes mencionada) les había insultado: “¡Luis ladrón (el esposo de la bruja)! ¡La vaca de mi hermano me has robado! ¡Lino trompa!”. No había robado la vaca: el animal había pasado al cerro de Liqe; mi papá lo había culpado sin motivo. La señora del Luis viniendo a nuestra casa, a mi papá le ha castigado con un palo: “Ahorita te voy a matar con este palo, por habernos tratado de ladrón!”. Le ha golpeado como a su querido a mi papá. 
De eso lo han embrujado a mi papá. Mi papá, a causa de esa embrujada [sic] se emborrachaba con un vaso de chicha, y les insultaba, los molestaba a todo el mundo, a nadie le tenía miedo; por eso la gente decía: “¡Ay, ese Marcelo ya está viniendo, saquen la chicha más simple y guarden la mejor!". Todos le odiaban a mi papá porque se enloquecía cuando se chupaba.

Porque cada vez que se embriagaba mi papá se volvía malo, loco. Hemos recurrido a un curandero. El curandero se llamaba Marcelo Ramos, tenía el mismo nombre de mi padre. [...] El curandero nos ha dicho que "esto es embrujado, vamos a sacar". El muñeco embrujado le habían colocado en la cocina, donde solía sentarse mi papá, de ese lugar ha sacado el curandero. El brujo había hecho el muñeco de su sombrero y de otras ropas de mi papá; había confeccionado parecido a mi papá. Una cruz en miniatura amarrada con una pita torcida a la izquierda, había colocado donde su corazón. El muñeco, la cruz, la pita todo esto le había teñido de color negro. Después, su cabeza y sus miembros los había doblado hacia su pecho y en el interior del muñeco el excremento de persona, posiblemente de mi papá; todo esto envuelto en una tela negra bien cosida con una pita negra. Esta tela negra era de su aymilla [camisa] de mi papá. ¿Cómo nos habrían robado su aymilla de mi papá?

El curandero apenas sacó, rezando y rezando, ese muñeco, o ese brujerío; el curandero temblaba mucho al momento de sacar. Y mucho hedía ese objeto; nosotros le hacíamos esperar una olla de orín, sal y sulfato de alúmina, entonces ahí metió ese brujerío. Nosotros le decíamos al curandero: “PPor qué tiemblas?". Él nos decía: "El demonio está por quitarme”, por eso rezaba para sacar. Después, cortando el hechizo, hemos visto; mucho hedía. Mi papá también ha visto. Desde entonces mi papá se curó de lo que era loco al emborracharse: ese curandero le curó a mi papá y así mejoró.

La confección del muñeco parecido a la víctima, la utilización de las ropas de esta, el entierro del muñeco en lugar próximo al embrujado, el hedor, son por cierto ya lugares comunes de la brujería. Y en este caso de la brujería andina, todo hace pensar en una fuerte influencia de la brujería medieval europea, sin perjuicio de elementos propios (la pita torcida a la izquierda -llamado lloq'e en quechua y considerada con diferentes propiedades mágicas-, los ingredientes usados en la olla, el uso de miniaturas).

Las persecuciones del brujo a su víctima. Este tema reafirma, igualmente, el carácter de construcción predeterminada de situaciones fantasiosas de estas producciones:

\footnotetext{
...esta vez a la bruja sabíamos escucharle; venía haciendo bulla - “jiqi, jiqi, jiqi, jiqi”. Y mi mamá: "Ahí viene tu amante”, le decía a mi papá. Nosotros toditos estábamos echados en el patio escuchando. Y mi papá le decía [a mi mamá] "Déjale a tu hermana”. Ahí arriba, en la esquina de la vaquilla muerta, la bruja está sentada: "Jiqi, jiqi, jiqi, jiqi”. Mi mamá: “Excremento del demonio, rana amarilla! ¡Cómo me lo van a embrujar a mi esposo! ¿Acaso era tu amante?”, así le gritaba desde nuestra casa, lanzándole en una honda sal y millu [sulfato de alúmina].

[...] Teníamos un primo hermano llamado Félix; era hermano de nuestro primo Sebastián. Bueno, él estaría andando de noche, como todo joven. De noche había ido hasta Pitukuno a la casa de su amada María, y cuando estaba yendo allí, la bruja Francisca le había cruzado hacia nuestra casa, emitiendo su voz de bruja "jiqi, jiqi, jiqi, jiqi”. Nuestro primo: “ ¡Carajo de mierda, puta! ¿Qué queriendo andas? ¿La bruja Francisca eres, no es cierto?”, le había dicho. Y cuando le había dicho así, la bruja: “Tú qué tienes que hacer? No es a ti a quien estoy yendo a embrujar, a Mariano Choque", diciendo esto le había cruzado. De ahí nosotros nos enteramos de que nos estaba embrujando.
}

\section{EL MODO DE NARRAR Y ALGUNAS PRIMERAS CONCLUSIONES}

Hay una última observación que queremos hacer en este primer análisis de los relatos de brujería. Es sobre el "modo de narrar" del relator. Desgraciadamente estos textos solo transcriben a la palabra escrita grabaciones magnetofónicas iniciales. Tampoco es un registro en vídeo. De manera que se pierden todas las inflexiones del narrador, sus gestos, entonaciones, las miradas, los énfasis, todas sus actitudes corporales. Pero en nuestro caso, que recogimos personalmente algunos de los relatos, nos era evidente el esfuerzo de Felipe, por ejemplo (uno de los relatores), por convencerme no solo de la verdad de los hechos relatados, sino también por hacerme llegar lo espeluznante de la narración, por impregnarme del horror de los hechos de brujería mismos. En la relación de interacción que se establece en el relato de brujería, la acción del relator sobre el oyente, por medio de la palabra y el gesto, tiene el propósito de hacer experimentar a este último el espanto que inspira la figura del brujo.

Está pues claro que estos relatos de brujería no solo son construcciones de verosimilitud (textos destinados a hacer creer que son verdaderos), sino también construcciones de impacto emocional, destinadas a producir un sentimiento muy cercano al horror. Es obvio que para oyentes que no pertenecen a la cultura andina, algunas de las figuras utilizadas en estos relatos pueden resultar algo ingenuas y nada de aterradoras. Lo que desde luego no ocurre con el público andino de estas narraciones. Pero también es posible encontrar en uno mismo las fibras del terror: leyendo o escuchando estos relatos me es muy fácil recordar los cuentos de miedo que me contaban las criadas, de noche, cuando yo era pequeño, y lo espeluznantes que me resultaban. Pero no hay que ir tan lejos: pensemos en el éxito que tienen ciertos programas bien hechos, de terror, de la televisión actual. Pienso que el terror es siempre algo más que una vivencia culturalmente condicionada, y parece tener bases psicosomáticas casi a flor de piel. 
La impresión de espanto es acentuada por la ocasión (tiempo y lugar) en que se narran estas historias. De noche, en grupos pequeños, en la soledad de una casita apartada, y bajo la motivación de percepciones extrañas como ruidos anormales, o luces sin causa aparente.

También está claro que los relatos de brujería no reflejan necesariamente acontecimientos de brujería realmente ocurridos en las comunidades. El estatuto de la verdad (veridictorio) que tienen estos relatos, es que "parecen" crónicas de brujería, pero "son" narraciones de construcción de una significación de fantasía dentro de un universo mágico/mítico. Pero la cantidad de relatos parece sobrepasar, con mucho, los hechos prácticos de hechicería (en que alguien manipula palabras u objetos para cambiar la suerte de otro) en el seno de las comunidades estudiadas. Y, más aún, y esto es interesante, se tuviera la impresión de que estos relatos (tal vez conservados con sus variantes y transformaciones a lo largo de los años) son el "modelo intelectual" que orienta las prácticas de causar el mal. Y como modelo, afectan al tema principal que ha suscitado esta investigación -los conflictos de carácter sobrenatural en las comunidades andinas, que implican manipulaciones de brujos, y castigo, a veces mortal, dado por la comunidad-, ya que, como veremos, a menudo se refieren a justicias realizadas por el grupo, sin pasar por la justicia ordinaria.

\title{
Los castigos a los brujos (en los relatos de brujerías)
}

Aún más, en todos los casos (quizás salvo uno) de historias que terminan con la muerte del brujo, todos los castigos o ajusticiamientos llevan la marca de las piezas del repertorio de figuras estereotipadas: son ya figuras hechas de esta clase de relatos. Un entrevistado dice:

\begin{abstract}
...Así nos contaba mi papá. También nos contaba que antes los comunarios eran solidarios. Si en la comunidad pasaba algo grave, entonces la comunidad se reunía para dar solución y dar justicia, incluso hasta los quemaban a los brujos: ahí terminaban las hechicerías. Nos contó mi papá lo que habían quemado (a un brujo) en el valle de Qori Punku. Cuando lo habían quemado entre todos, jaloneando donde estaba ardiendo el fuego, por tanto jaloneo sobre el fuego, del cuerpo del brujo habían saltado tres gatos amarillos. Al ver esto la multitud no sabían qué hacer. Se habían asustado. Por lo menos, así se defendían antiguamente. Pero ahora no hay.
\end{abstract}

En otra parte, el mismo entrevistado cuenta ya no un ajusticiamiento, pero un castigo a un brujo: "Bueno, en el valle hay esa solidaridad, pero yo no he visto lo que me ha contado mi padre. En el valle a un brujo lo hemos castigado, decía, le hemos hecho tomar orín fermentado, con sal, azufre y otros. Le hemos hecho pasar por encima de vara de justicia, le hemos hecho hacer juramento, así nos contaba mi padre. Así se debe hacer en la puna; aquí son muy temerosos".

Castigos de este tipo -que no implican el ajusticiamiento del brujo- se repiten con gran frecuencia:

Florentino Churqui se llamaba ese brujo. Él sabía curar, este Florentino, y al curar él acostumbraba a pedir por su servicio una vaca. Él curaba completamente, pero pedía una vaca como pago. Una vez, un hombre le había dado una vaca, y él arreó la vaca hasta Quila Quila. Allí había un congreso, que era muy grande, para el cual llegaron los sindicatos, los centrales de muchos lugares... Y allí empezaron a hablar del jampiri. ${ }^{9}$ Había un dirigente, Luis Ramos, que sabía esto. El era de Maragua. El jampiri le dijo "Tú no vivirás mucho. ¿Qué hablas tú de mí?”. El jampiri decidió cobrarse la vida del dirigente. Antes de venir, los dirigentes de Chaunaca y Tumpeca, le hicieron curar. Ya en el lugar mismo, denunció al jampiri: "Nosotros sabemos qué es lo que ha hecho", diciendo. La gente del lugar lo cogieron y persiguieron al jampiri. Esa persona contó lo sucedido a los dirigentes, diciendo que "a mí también me sacó una vaca, porque no tenía dinero y no me curó [...] Dice que siempre que cura pide una vaca". Después, lo trajeron hasta Maragua; estaban reunidos en Maragua los dirigentes de Umaca, Tumpeca y Chaunaca. En reunión decidieron darle un castigo. Ahí también se equivocaron los dirigentes. La gente hablaba de lo que sabían, habían escuchado todo tipo de comentarios. "¿Qué hacemos?". Lo cogieron, le hicieron tomar millado, millu [sulfato de alumbre] incluso jabón, agarrándolo le hicieron tomar. De ese modo lo castigaron. Fue así.

El relato muestra la intervención de dirigentes sindicales y autoridades de las comunidades. Pero el asunto no llegó a mayores; según terminaron de contarme la historia, ese brujo huyó y ya no volvió a aparecer. Sin embargo, en varios relatos, el entrevistado se queja de la indiferencia y pasividad de los dirigentes hacia los hechos de brujería. Pero, como mencionábamos, otras narraciones terminan con la muerte del culpable. Una de estas historias no deja de ser sorprendente:

P.- ¿Nunca usted ha escuchado de que a una bruja la ha castigado la comunidad?

R.- Han castigado, es lo que decían. Un brujo, era eso lo que decían.

P.- De esto ¿̨cuánto tiempo ha pasado?

R.- Esto estaría por los años del 67. En esos años ha pasado más o menos. De Vila Vila, por ahí es. De la tranca, más allá es. 
P.- ¿Cuál habrá sido la razón para castigarlo?

R.- Dice que era capo para hechizar. En 24 horas liquidaba, decían.

P.- ¿Solo en 24 horas?

R.- Sí; en 24 horas estaban servidos y han muerto.

P.- ¿Harto daño ya habrá hecho esa vez?

R.- Harto daño ya había hecho; se han muerto hartos.

P.- Pero cuando le han castigado ¿qué tipo de castigo le habrán dado?

R.- Dice que le habían agarrado, le habían atado sus manos. Eso han hecho los curacas de esos sindicatos subcentral. Y le han amarrado después, y le habían empujado al fuego.

P.- ¿Atizando fuego le habían empujado?

R.- Sí. Lo habían atizado al fuego. Pero no le han hecho nada. Eso es lo que han hecho.

P.- ¿Solamente han hecho pasar por fuego?

R.- Lo han hecho pasar empujando por el fuego. Según que dicen, él mismo ha salido con más fuerza del fuego. Y la gente se había asustado y se había escapado. Y no le han hecho más nada.

P.- ¿Es decir, que ha tomado más fuerza dentro del fuego?

R.- Sí. Dice así.

P.- ¿Y no le han dejado alguna señal al ser atizado al fuego?

R.- Poquito señal le habían dejado.

P.- ¿No le han dado algún otro castigo más?

R.- El único dice que le han dado.

P.- ¿De eso habrá olvidado o habrá dejado de hacer daños?

R.- Seguía, dice. Por eso, cuando tenían que matar algo de carnear, primero tenían que llevar a él la carne o lo que sea.

P.- ¿Al brujo?

R.- Sí.

P.- ¿Si no le llevaban?

R.- Dice de eso es lo que hacía, pues. Les hacía tener miedo, pues.

Hay muchos otros relatos con finales semejantes, pero todos producen la misma desconfianza sobre su realidad.

R.- Esto [este relato] es del señor del wayq' $u^{10}$ Bueno, un día en Quila Quila dice que había, cuando mi mamá era como ella [señala a una señora que asiste a la entrevista, como de 40 años], había una bruja. ¿Qué era su nombre? Enrique, o algo así [sic]. Dice que embrujaba a todas las personas que iban por el wayq'u. Enviaban a los alcaldes, pero no sabía hacerse caso más bien de ellos: se asustaban. Al final decidieron ir donde el cura; dice que había un párroco. "Lo cogeremos", se dijeron los dirigentes y el cura. Al enterarse de sus propósitos lo embrujó al cura. El cura no se levantaba de la cama: estaba todo hinchado, era su castigo. Entonces los alcaldes caminando todos se reunieron para hablar con el cura. Así se reunieron los corregidores, todas las autoridades que habían. Se reunió toda la comunidad. Agarrándolo, al fin lo llevaron, al fin lo cogieron. "Lo quemaremos", diciendo. Reunieron leña y encendieron el fuego para calentar el horno. Solo así habló. "Sí, lo hice porque el padre habló de mí". "¿Cómo lo hiciste?" - "Reuní todas sus ropas para hacer un muñeco y enterrarlo". Entonces, él mismo los llevó al lugar donde había enterrado el muñeco. Mientras el horno seguía ardiendo lo agarraron al brujo y gritando se quemó en el fuego. Y ahí termina.

P.- ¿Lo quemaron vivo o muerto?

R.- Parece que vivo, porque si se salía del horno seguiría embrujando.

P.- ¿Directamente lo botaron, o lo amarraron?

R.- Seguramente gritando y revolcándose murió. Así termina la historia del brujo.

Es, pues, evidente, que el tema del "ajusticiamiento de brujos" es un motivo más de los relatos de brujería. Y no parece tener ningún apoyo como práctica consuetudinaria en las comunidades andinas. Y aunque no tenemos todavía una investigación etnohistórica sólida, sospechamos que este uso carece también de antecedentes en la época prehispánica. Más bien este ajusticiamiento de brujos, esta quema de brujos y brujas, huele demasiado todavía a las hogueras de la Santa Inquisición española.

Y sin embargo, todos, o casi todos los relatos de brujería, terminan con el ajusticiamiento de brujos, aunque más no sea que como "motivo". ¿Cómo entender esta situación? Creo que ya se ha insinuado una respuesta. Los relatos de brujería, en tanto construcciones de significación que son, son también construcciones de ideología; de una ideología que parece deber su origen a la influencia de la iglesia española, particularmente aquella del siglo XVII, tan decididamente interesada en borrar los cultos autóctonos y perseguir "idolatrías". La definición de los brujos como "aliados del diablo", y la identificación de este con los dioses tutelares, son argumentos que sirvieron estupendamente para profundizar la fortaleza de la fe de los indígenas en la iglesia. Y por último, el ajusticiamiento de un brujo entre las llamas de un horno, es un final acorde con una lógica que arrastra todavía fundamentalismos de la reconquista ibérica y del sometimiento de árabes y judíos como antecedentes del aplastamiento andino.

Pero hay una reflexión más que suscita esta especial situación de los hechiceros en los relatos. De alguna manera los relatos de brujería parecen basarse en una necesidad cultural y espiritual profunda sentida por la gente andina. Y si no hubiese "brujos de verdad", no sería extraño que la gente estuviese dispuesta a crearlos, recayendo en alguien de la comunidad el estigma de la brujería con el único fundamento de la maledicencia. 
Quiero decir que basta con la sospecha malintencionada, basta con la animadversión mal fundada, basta con los oscuros resentimientos, para "hacer de una persona un brujo", que "merece" ser perseguido. Lo que sugiero aquí es que en la noción misma de brujería, en la concepción misma de esta condición, está contenido el germen de la persecución, del castigo y hasta del ajusticiamiento, sin fundamentos. Y aunque según nuestro punto de vista el ajusticiamiento pocas veces se produce en la realidad, están dadas las condiciones psicológicas para que una asonada de un grupo de personas se sobrepase tomando la justicia en sus manos. Pero en este caso, el ajusticiamiento -si es que llega a producirse- y en general la persecución y el castigo al brujo, tienen todo el halo de una situación sacrificial (Cristo, Juana de Arco, los Katari). Estas sugerencias, naturalmente, deben dar paso a un estudio más específico y profundo de este tema.

\section{LOS HECHOS DE BRUJERÍA}

\section{Los brujos de verdad}

Hasta ahora no tenemos evidencias suficientes para afirmar que en las comunidades se produzcan, con frecuencia o sin ella, conflictos sociales motivados por la acción supuesta de un brujo. Con estas palabras no estoy queriendo decir que no los haya, ni que no los haya habido en un pasado reciente (la mayoría de los relatos se refieren a supuestos hechos ocurridos entre hoy y hace 30 o 50 años). Pero hasta ahora, en nuestro material de entrevistas recopilado no nos ha aparecido ningún caso irredargüible de ocurrencia de esta clase de conflictos.

Ahora bien, los principales argumentos que he sostenido hasta aquí -que los relatos de brujería son creaciones culturales colectivas de significación mítica, y que no corresponden necesariamente a hechos de brujería realmente ocurridos en una comunidad- conducen obligadamente a algunas preguntas cruciales: ¿es que entonces no hay hechos reales de brujería, prácticas más o menos normadas de hechicería, independientemente de sus posibles o no posibles resultados? Por consiguiente ¿tampoco hay "brujos de verdad" que produzcan realmente daño a las personas? En estas interrogantes tenemos que distinguir dos aspectos. En primer lugar, las personas especialistas en tratar de causar un daño a otra persona, a un grupo o a una colectividad. No niego aquí su existencia, pero es muy difícil tener acceso a su ritual específico, ya que es delictivo. Y por supuesto que ningún brujo "de verdad" se da a conocer abiertamente como tal. Ningún brujo se presenta diciendo "Manuel Mamani, brujo de verdad, para servirle, señor". La característica del brujo es, precisamente, que actúa "en el secreto". He tenido, sin embargo, una experiencia cercana, pero, en cierto modo, diferente: algunos objetos desaparecieron de una casa y fue opinión de la gente conocedora del ayll $u^{11}$ donde ocurrió el suceso que era necesario traer un brujo de afuera para que las hiciera aparecer. El brujo extrajo una calavera del cementerio de su pueblo y la colocó en una especie de capilla, con tres velas encendidas y crespones de papel morado. Lo más importante, sin embargo, fue el paso siguiente: hizo enviar emisarios a todas las estancias ${ }^{12}$ cercanas promulgando que el culpable moriría al cabo de veinte días si no devolvía el robo. Los objetos no eran de gran valor, pero lo que estaba en juego era la confianza de los dueños de las casas del pueblo principal, que las dejaban casi deshabitadas todo el año, confiando en que no podría haber robos al interior del ayllu. Los objetos aparecieron a los diez días, dejados en una calle por la noche y nunca se supo quién fue el culpable. El oficiante podía ser considerado yatiri, ya que trataba de "hacer un bien": devolver la confianza a la comunidad; pero, por otra parte, amenazaba con provocar una muerte, y de este modo caía en la clasificación de los brujos. Es decir, las prácticas existen, pero, como lo desarrollo más adelante, en muy menor escala que los textos orales que se refieren a ellas.

Por otra parte, los resultados. Prácticas de magia negra y personas que las ejecutan deben, en términos de un análisis, ser independizados de los efectos que ellas producen. El impacto psicológico (que hizo al ladrón devolver lo robado en la anécdota anterior) pertenece, en realidad, a otro tema que no podemos abordar aquí y que sería materia de un trabajo interdisciplinario con una etnopsicología. Me refiero a la eficacia de la magia.

Otras consideraciones permiten postular la existencia real de brujos y sus manipulaciones. Una de ellas es el hecho de que no parece haber sociedades sin ninguna clase de personas que realmente manejen el mal contra otras, utilizando técnicas así llamadas mágicas, como también la intuición, frente a ciertos relatos de brujería llenos de detalles, de que ahí hay el rastro de una experiencia con algún ser maligno. Esto lleva la problemática de la brujería andina a situarse en valores de la cultura que oponen "bueno vs. malo". Siguiendo otros ejemplos de oposiciones andinas, podría pensarse que también en este caso se trata de un paso fluido, con una gran gama 
de valores intermedios entre uno y otro extremo de la oposición. Pero el estilo de la brujería en las comunidades actuales, influida poderosamente por las concepciones europeas, podría representar, tal vez, una presencia de "lo malo" más esencialmente malo, más absoluto. Esta estructura de valores es la que organiza el sentido profundo de estos relatos de brujería, a partir de la cual se crea tanto la sustancia dramática de estas historias como su peculiar colorido emocional. Un trabajo más exhaustivo sobre este tema debería abordar esta relación de la brujería andina con sistemas éticos que le son pertinentes.

La impresión que yo tengo, sin embargo, es que los brujos "de verdad" y los hechos reales que puedan protagonizar, se pierden en la maraña de los hechos relatados, o de los hechos construidos en el imaginario cultural.

Lo que estoy queriendo implicar con esto es que los relatos de brujería no se quedan tan solo en la dimensión relato, o en la construcción verbal de una significación mítica, donde, sin duda, tienen su realidad. Ellos traspasan, o tienden a traspasar esta dimensión, para adquirir una suerte de "realidad real" en la referencia a las relaciones interpersonales en una comunidad, con las cuales se entretejen. El hecho es que muchos de los conflictos sociales entre personas en una comunidad son explicados por causas de brujería. O quizás al revés: suposiciones de brujería son explicadas por conflictos interpersonales. Así, por ejemplo, en la siguiente entrevista, un hechizamiento parece surgir a raíz de problemas al interior de una familia:

R.- Al saber de todo esto [del daño mágico que un pariente político le estaba haciendo al padre de la entrevistada] hemos empezado a investigar mediante otros yatiris de todo lado. Exactamente no me acuerdo de qué lugar era el que sabía "rastrear" (leer la coca), pero el señor era de la zona baja. Así nos dijo cuando hemos hecho rastrear en coca. Nos confirmó que podía sacar (el brujerío), pero por un precio caro. Aún así hemos hecho sacar y ha sacado por 500 Bs; pero ha sacado, como nos había dicho.

P.- ¿Como qué cosas ha sacado?

R.- Bueno, como ya les estaba diciendo, ha sacado cruz, hechos en un trapo bien envuelto; de ahí ha sacado cabellos, pedazos de nuestras prendas de ropa, en eso cada cual hemos reconocido nuestras ropas. Juntamente dentro de esos había cabellos, cruz hechos de alambre, hechos de yunka, ${ }^{13}$ espejo, juntamente había, azufres, inciensos, kutis $^{14}$ había de todo; en su mayoría yo no conozco, no sé sus nombres de esos ingredientes.

P.- ¿Cuál hubo la razón para que haga hacer ese daño?

R.- Bueno, como que en cada familia no siempre podemos vivir bien bonito, por mucho que seamos hermanos de un solo padre y madre. Ocurrió de reparto de tierras como un quitoneo entre ellos, de la familia. Eso ha debido ser la razón para que le hagan hacer. Hay un caso más: que dentro de esa familia había sido el único hombre mi padre, los demás eran puras mujeres. Por eso, por ser mayoría de las mujeres, entre ellas se habían repartido la tierra y a mi padre no le habían hecho tocar. Y esta familia, que habían sido conocidos por pudientes, por eso tenían harta oveja, no disminuía de sobre trescientos cabezas. Como de los ganados, era siempre sobre treinta para arriba. Todo eso no habían hecho tocar a mi padre. De eso mi padre se había enojado. Y una de sus ovejas se había juntado a la tropa de mi padre. Y de rabia mi padre lo había carneado, por lo que no le han hecho tocar nada. Y mi madre no había comido, seguramente nosotros tampoco. Mi madre era caprichosa, por eso no nos había hecho comer.

\section{Parecida es la situación que nos relata otra entrevistada:}

P.- Para que esto sea más claro ¿qué es lo que ha pasado con tu padre?

R.- Se puso a enfermarse un buen tiempo. Sentía del estómago, le dolía; de poco a poco se puso más enfermo. De eso se hacían rastrear en coca para saber quién era, o de qué era. En cada rastreada nos salía que no era una enfermedad sana, sino estaba hechizado, estaba embrujado. Cualquier curandero siempre nos decía que era embrujado. De esa manera se ha descubierto quién nos ha hecho. Ha salido en claro.

P.- ¿Bastante tiempo es lo que se ha enfermado tu padre?

R.- Casi como dos años se ha enfermado, o tal vez más. Pero hacía largo tiempo que se ha enfermado.

P.- ¿De qué es lo que más sentía, qué parte de su cuerpo?

R. Del dolor del estómago. No podía aguantar, sufría harto. Por lo que no podía aguantar caminaba de cuatro pies. Ya de bastante tiempo se ha sabido que había sido embrujado. Su mismo marido de mi tía le había hecho ese daño. Así se ha afirmado.

P.- Para que esto se sepa más claro qué han hecho ¿̨han hecho rastrear con otro yatiri, con cabildero? ¿Cómo han sabido que era cierto de su mismo tío le ha hechizado?

R.- Hacían rastrear coca, pero cualquier yatiri nos decía que es él el que ha hecho daño. Todos nos afirmaban que era él. Es así. Cuando se ha enfermado mi papá, ese mi tío nunca sabía venir siquiera a visitar. Por lo que se ha enfermado, se reía de mi padre. No le hacía caso para nada a mi padre. De esa manera hemos creído que de verdad ha hecho él. Además ya era más claro de ese mi tío.

Notemos aquí -como en otras entrevistas- que la identificación del brujo se deduce de procedimientos tan sobrenaturales como el hechizo que se le supone: en este caso, el "rastreo" en coca, es decir, tirar las hojas de coca para interpretar en su caída una respuesta a una pregunta. Es ese rastreo quien señala al culpable, con toda la arbitrariedad que esto supone. Y con todas las consecuencias de estigmatizar a alguien del grupo.

P.- ¿Cuál ha debido ser el motivo?

R.- Esto es sobre el caso de tierra. Se han quitoneado parcelas. Como que además, cuando se han muerto mis abuelitos, no les ha ayudado en nada en su entierro. Además, como mi padre era el único hombre de la familia, por eso le han hecho tocar más grande 
a mi padre. A mi tía le han hecho tocar menos, por lo que era menor de todos, y por lo que no se ha ayudado en el entierro. De esa forma le había hechizado a mi padre.

P.- ¿Qué cosas han encontrado, en lo que ha hechizado?

R.- Hemos llevado un curandero que sabía bien. Para eso hemos buscado harto, para llevar hasta allá. Ese curandero ha sacado de un trapo bien amarrado, nuestras cosas de ropa. Cada cual nos hemos reconocido nuestras prendas. Sí, de esa manera he creído yo también. Eso han sacado de dentro de la tierra: había sido enterrado, de eso le creí, porque antes no creía.

P.- ¿Qué prendas han encontrado en lo que han sacado?

R.- Han encontrado pedazos de prendas de mi hermano Roberto, de mi mamá, como que antes mi mamá usaba la ropa de bayeta de almilla; de mi padre han encontrado un pedazo de su calzona hecha de bayeta. Así, toda clase de prendas.

P.- ¿Con qué cosas estaba envuelto?

R.- Bien envuelto en un trapo con medicamentos de hechicería; ha encontrado cabello. Había toda clase de ingredientes, azufres, un montón de cosas hediendo. Han sacado.

P.- ¿De eso has creído recién?

R.- Desde esa vez creo, viendo lo que hemos encontrado. Además, él mismo [el tío] ha hablado de borracho. Había confirmado que ha hecho él, que él hizo daño a mi padre. De eso se ha sabido más claro. Desde esa vez hasta ahora no sabemos convivir. No nos llevamos bien desde esa vez, ni por saludo. Aún peor con nosotros, no sabemos siquiera mirarnos. Desde esa vez, toda la familia de nuestra parte le odian por lo que es dañino.

Otro informante nos da una visión de relaciones sentimentales bien plausibles para un embrujamiento:

P.- ¿Cuál ha sido el motivo para que le embrujaran a tu tutor?

R.- En su tiempo de juventud había tenido su novia y justamente había sido la bruja. Y en esa bruja había tenido un hijo. Sí, a esa mujer decían que era bruja, llamada Jesusa.

P.- ¿Esa su novia era la bruja?

R.- Sí. Además el hombre, ya cuando era de edad no podía darle nada, y por otra parte sus terrenos eran colindantes. Como eran colindantes, siempre se veían el hombre con esa mujer. El hombre poco a poco se ha enfermado; durante un año se ha enfermado. P.- ¿Qué parte de su cuerpo es lo que más sentía?

R.- Lo que más sentía de su cuerpo, escupía como pus, tenía un tos seco, no podía aguantar de su pecho, esqueleto se ha vuelto el hombre. No comía, durante un año. Después se ha muerto.

P.- ¿Su familia también se ha muerto?

R.- Se ha muerto también de esa familia. Todos se han muerto, nadie se ha quedado de la familia; como soy su criado, conozco. Por eso le digo que todos se han muerto, ahora ya no hay nadie. Este mi tutor tenía harto ganado, siempre tenía de treinta cabezas arriba. Como también tenía hartas ovejas, tenía también hartos burros, sus caballos. Tenía un solo hijo varón, hasta ese su hijo se ha muerto. En verdad, nadie ha quedado.

P.- ¿Qué pasó con la bruja después?

R.- Después la bruja también se ha muerto. Tenía sus hijos. Esos sus hijos se han ido a Santa Cruz, nunca más han vuelto.

P.- ¿¿Será que se ha muerto porque le han devuelto la hechizada?

R.- No sé qué será; se hacían curar con otro curandero, como lo digo. Que de esa bruja que tenía sus hijos ya no viven en la comunidad, viven en Santa Cruz. El otro curandero también se ha muerto. La bruja Ramona también se ha muerto, dejando sus tierras se ha ido. Así es.

P.- ¿Como cuánto tiempo habrá embrujado?

R. No sé muy bien. [...] A mi tutor su mujer le decía: "Tu chola te ha embrujado, por eso estás así pues". [...] Así su mujer de mi tutor le reñía llorando, que "por tu chola estás sufriendo, ahora tu chola te tragará pues, que te coma pues, que te lo trague pues, a mí más me tragará pues"; así sabía escuchar.

Una concepción así de los hechos de brujería como acciones y situaciones absolutamente entretejidas con las relaciones sociales interpersonales entre los miembros de una comunidad, y de los brujos como agentes interactuantes en estas relaciones, es el complemento de las concepciones míticas. Algunos entrevistados demuestran tener conciencia de que los brujos aprovechan los problemas entre familias o entre vecinos, para ofrecer y vender sus prácticas, como se desprende del diálogo que sigue:

P.- ¿Tú alguna vez has visto o sabes escuchar de decir que tal persona había embrujado a tal persona, o había hecho embrujar a tal persona? ¿Escuchaste alguna vez?

R.- Sí, escuché cuando yo era pequeño. Tenía mi papá tutor Ignacio Calvimontes y su vecino Carlos Mostacedo. De ellos sabía escuchar no vivían bien... Siempre eran peleados. Cuando yo era chango todavía se decían de ambos que al otro le habían hecho hechizar con tal persona. Es decir, se achacaban de ambas partes, cada cual se sentían embrujados. Entonces el aysiri les decía a ambos "Vamos a devolver la hechizada, y hay que hacer así, de tal forma". Así les decía a cada cual. Como yo era todavía menor no sabía qué eran las embrujadas, por eso no creía tanto. Pero ninguno de los vecinos ha muerto. Es que los yatiris para ganarse plata de fácil siempre recurren a pretender de curar y devolver la hechizada.

P.- ¿Como cuántos años ha pasado de esto?

R.- Esto debe haber ya pasado como treinta años.

P.- ¿A qué persona le culpaban como malhechor que hacía daño? ¿Era hombre o mujer?

R.- Bueno, decían que cada cual de los vecinos tenían sus propios aysiris; que con esos sus aysiris se hacían embrujar. Así se culpaban. Bueno, había un curandero yatiri del lado de valle misa, llamado Leonardo Mamani. Era un llamero este yatiri; les hacía creer. En realidad no sé si sabría hacer las hechizadas o no. Pero ninguno de los dos vecinos no ha muerto. Pasó un buen tiempo. Después de muchos años este don Ignacio se ha muerto. El tenía otro hermano, Carlos. Este también se ha muerto. Tenía también 
otra hermana; ella también se ha muerto, pero ya en edad avanzada. En realidad no sé si será por la embrujada. Qué será, no sé. Pero ambos enfermando se han muerto. Pero ese aysiri les decía que eran embrujados en vena, para que toda la familia pueda morirse. Con ese pretexto decía que estaba curando y que estaba devolviendo la hechizada; al decir esto, hacía sus cosas. Pero esa familia se ha muerto; como que todos tenemos que morir. Como que esa familia o las personas se han muerto ya en edad avanzada. Si tenemos que morir con la enfermedad de dios, creo que todos vamos a morir en ese camino si dios nos destina de esa manera.

\section{La "materialidad" de un brujo: su aspecto físico}

En un momento determinado de la investigación me interesó vivamente el tema del aspecto físico del brujo, su apariencia a los ojos y a la percepción de los demás miembros de la comunidad. ¿Cómo veía la gente al brujo? Como era de esperar, también aquí nos encontramos con una construcción fantástica del horror. Me encontré, muy al pasar, con algo que se acercaba a una descripción de la imagen que yo buscaba. Y los términos son verdaderamente impresionantes. Están en la oración que un ch'amakani ${ }^{15}$ ofrece a las deidades para levantar una maldición de brujería, en la comunidad aymara de Irpa Chico. A mitad de la oración en la "mesa negra" que ha preparado, el ch'amakani dice, refiriéndose a los brujos:

Jesús Dios Padre, Espíritu Santo, has de mascar esta tu coca. Todos los que maldicen, todos los que envidian, hombres o mujeres. A toda persona recordada y no recordada que en este momento no sabemos su nombre. Bueno, aquí está la hoja. Has de mascar. Luego los malignos. Así también todos los malignos, los que miran con rencor. Lo mismo en los pajonales del ganado. Los que miran existen, de la manera de caminar y mirar a todos lados. Todos los que maldicen, hombres y mujeres.

Las oraciones en cursiva se refieren a los brujos. Lo que en este momento nos interesa particularmente de esta cita, es la descripción de la manera de mirar y caminar del brujo, que es en extremo sugerente y bastante siniestra. Pese a la variedad de rasgos, que aportan otras descripciones, hay imágenes comunes que reafirman el carácter ominoso del aspecto físico y comportamiento. Distintas entrevistas contribuyen a completar esta imagen:

P.- Pero ¿cómo miraba la gente, qué decían de la bruja?

R.- Pero yo era chango todavía esa vez, de chango la he conocido. Me hacían ver que era bruja, mi abuelo me decía que su cabeza se reventaba. Es lo que decía. Por lo menos esa vez la abuelita estaría de 80 años o de 75 años. Abuelita era, pues.

P.- ¿Cómo era la abuelita, para distinguir?

R.- Era flaquita la abuelita.

P.- ¿Tenía alguna señal?

R.- Nunca he curioseado.

P.- ¿Nunca te has fijado?

R.- Dice que tenía, pero.

P.- ¿Se puede distinguir, pero?

R.- Sí. Se dice que tiene una raya en el cuello.

P.- ¿Como una marca?

R.- A mí me han dicho que tenía una marca en el cuello, como cicatriz. Delgadita dice que es.

P.- Como otros también dicen que se puede notar en el ojo a una bruja. ¿Será cierto?

R.- Sí, dicen que da vueltas a sus ojos.

P.- ¿Al menos en el color del ojo se puede conocer?

R.- Sí, porque dicen que se saca, para cambiarse con otro ojo. Con el del gato.

P.- Entonces ¿se dice que se sacan sus ojos?

R.- Para volar tiene que sacar sus ojos, para ponerse ojos del gato. Para volar.

P.- ¿Qué harán para hacer eso, no?

R.- No sé qué harán para hacer eso.

P.- ¿Con qué ingredientes harán? ¿Será que hacen q'owada, ${ }^{16}$ o algo?

R.- No sé eso.

\section{En otra entrevista:}

P.- ¿Cómo podemos descubrir, o en que se sabe que es brujo?

R.- Bueno, para saber que es brujo es claro ese brujo, en lo que hace, en su mirada, en su forma de ser como persona. Al menos la misma gente lo descubre por sus actos de lo que hace daño. Lo único es que no quieren aclararle que es brujo, sacar en claro que es brujo. Eso es por miedo. También por miedo de ser hechizados, por eso no quieren hablar.

P.- ¿Cómo se puede saber si es brujo o no?

R.- Para descubrir del brujo si es o no es brujo, es claro en su cara, en su ojo.

P.- ¿De cómo se puede saber en su cara?

R.- Podemos decir que en sus ojos es claro, es diferente, es su forma de ser como personas. Cuando se emborrachan ahí se hacen notar. En la misma borrachera quieren empezar con su oficio. Es en eso que se hacen notar.

P.- ¿Cuando están borrachos, ellos mismos se declaran, cuando están ebrios? 
R.- Sí, ellos mismos empiezan a confesar de lo que saben hacer, hay quienes ya lo ha hechizado, así empiezan a hablar de borrachos. Hay además, ha hecho hechizar a tal persona. O en su caso se ofrecen que se lo pueden hechizar. En estado de ebriedad cualquiera puede hablar. Lo que es difícil es de aclarar de sana razón.

P.- También me decías que se le puede notar en su forma de caminar. ¿Cómo se le puede notar?

R.- Se le nota. Caminan al estilo farsante; no son inquietos, siempre están mirando o curioseando cualquier cosa. Quieren que le respetemos. A veces por miedo le llaman: pase, señor tatay. ${ }^{17}$ Así quiere que le respeten. Se hacen orgullosos.

Lo decepcionantes que puedan ser ciertas respuestas, en algunos aspectos, se complementa con el aporte de otras entrevistas:

P.- ¿Hay algo más en que se puede notar a los que saben hechizar?

R.- Bueno, yo creo que se puede notar más en sus ojos, que son rojos. [...] También en lo que podemos distinguir es en sus miradas. Es distinto. Tienen una mirada durmiente, como si no hubieran dormido. Por eso sus ojos son rojizos. En su forma de hablar también es diferente. ¿Cómo se puede decir? Tienen una palabra altanera. No le hacen caso a nadie, son prepotentes. [...] De caminar, caminan con ciertos objetos, los llaman choqes. ${ }^{18}$ Caminan también con campanitas. Después trajinan juntamente con coca llamado inkhuña. ${ }^{19}$

\section{ANIMALES, BRUJOS Y DIABLOS}

En diversas entrevistas se ha ido delineando también la relación entre los brujos y ciertos animales, que les están asociados:

P.- ¿Qué piensas de sus ayudantes? ¿O quién les apoya a los brujos?

R.- Sus ayudantes de los brujos deben ser los diablos.

P.- ¿De parte de los animales?

R.- Los chukisusus, los búhos, q'iririnqa.$^{20} \mathrm{~A}$ esos animales les quería harto [un brujo que se murió]. Sabía agarrar a los búhos.

P.- ¿Los quería mucho a esos animales?

R.- Sí, los quería mucho, desde antes. Nosotros no nos hemos dado cuenta de eso. Para eso seguramente ya sabía de estas cosas de brujería. Esos animales deben ser sus ayudantes. Así pienso yo.

P.- [...] Es decir ¿¿de eso es lo que recibe poder, de eso tiene apoyo?

R.- Sí, de eso tiene fuerza. Saca calaveras de los chullperíos. ${ }^{21}$ De eso debe recibir apoyo. A sus t'ujlus ${ }^{22}$ debe convidar cuando quiera hacer daño a la gente. Para que mueran les pone velas a sus calaveras. Así dicen. Será que eso decía ñasq’o, mi ñasq’o. Así decía. P.- ¿A qué le llamaba ñasq'o?

R.- Le decía ñasq'o a su calavera, lo que ha sacado del chullperío. Seguramente esas calaveras deben ser hambrientas si son de chullperíos. A esos les convidan. Así decían.

No son los únicos animales de que se valen los brujos: “...y además, el brujo tiene en su poder animales como la víbora, lagartos, sapos. A ese sus animales el brujo les convidan cuando está hechizando. Así dicen”.

Estos animales son, pues, ayudantes del brujo. Pero, según se ve, son los únicos cooperantes que tiene. Hablando de ayudantes, en una entrevista, el entrevistador pregunta por otros ayudantes, de aysiris y del brujo. Las respuestas son aclaradoras:

R.- Solo es el brujo. Es solo.

P.- ¿Cuál es la misión del brujo?

R.- Lo que sea de hacer mal a la gente. Que nadie pueda juzgar. Es como un maleante. Como que el maleante roba solo; es igual solo, pues.

P.- ¿En lo que hace daño?

R.- Sin testigo hace, pues.

P.- ¿Por lo que no hay una ley para sancionar a los brujos?

R.- Claro, pues; al retorno [del brujo] ellos ya estaban investigando de quiénes habían muerto sus animales.

Para Carnaval ch'allaron ${ }^{23}$ toda la gente hace chicha en el campo. Ahora siguen haciendo chicha. Su sobrino, de quien murió la mujer. P.- ¿¿De qué tienen ayudantes los brujos?

R.- Los brujos no tienen. Los paqos $^{24}$ son de otros: de los yatiris. Esos son para que vayan a quemar los pollos y picharas ${ }^{25}$ que llaman, para que vayan a quemar en las puntas. El ayudante es el que va a quemar. El brujo no tiene su ayudante. Es como te digo: como un maleante que roba sin testigos. Sin testigos mata; igual son los brujos.

Esta imagen de la carencia de ayudantes y de la soledad absoluta del brujo es bastante sobrecogedora. Y es absolutamente coherente con la concepción general del brujo como un ser maligno que pertenece al diablo. Esta condición nos fue advertida, desde el comienzo, en una de nuestras primeras entrevistas, aquella del brujo que cuando niño se perdía gritando entre los peñascos y las cuevas. Cerca de terminar la entrevista, el relator cuenta: 
Sea lo que sea, estaba enferma la vaca [por obra del brujo]. Murió en su terreno, con el excremento seco. Debió ser dos días después, cuando toda la gente ya sabía lo ocurrido, y se preguntaron qué iban a hacer. "Haremos justicia", diciendo. Llegaron a Sucre a notificar a la policía. "Esas son mentiras. Ustedes están hablando sin motivo. iQué va a saber!" [Dijo la policía.] Lo trajeron a Sucre; él no decía nada. "QQué va a hablar! ¡Este tonto no dirá nada!". Sin razón lo arrastraron hasta Sucre De esa manera regresaron a la comunidad y su hermano, los jóvenes lo siguieron al verlo mareado por la ladera de abajo, por Rufuqa: después, por Qhuylulu. Rufo está al frente, y Qhuylulu está a este lado. Lo seguían por el frente y fue a la huerta al ch'allaku ${ }^{26}$ de su compadre. Y allí bebía él; su compadre sabía que mataba animales, pero él no pudo hacer nada y soportó la situación.

Bueno, esos carnavales lo cogieron. "¿Por qué me hacen esto a mí? Soy solo, murió mi mujer, murió mi wawa y también mi otra mujer", diciendo se quejó. "Matémosle de una vez", dijeron. [...] Entonces ellos fueron al ch'allaku en Rufu. Aún es notoria la huerta. Está a un lado del río. Lo condujeron allí donde estaban ch'allando. Y cuando se estaba por ir lo golpearon, le tiraron piedras hasta matarlo. Después de matarlo fueron a la casa de mi comadre a avisarle para que no se ponga triste. Llegaron llenos de sangre. "Vayan a Sucre a entregarse, no importa que nos denuncien", respondieron. Al oír esto los demás se sorprendieron y les invitaron chicha. De este modo se enteraron las autoridades, alcaldes. En esa época, dice que eran seis personas los alcaldes. Los alcaldes fueron al lugar; allí en el río está el muerto. Por la noche, cuando todos estaban bebiendo en las pukaras, ${ }^{27}$ se reunieron los alcaldes para ir a recoger al cadáver. Pero los demonios no les dejaron llevarse el cadáver; éstos empezaron a echarles con tierra. La gente quedó atontada. Al sacar al difunto, la gente llena de miedo lo llevaron a la cruz del Señor Santísimo. La gente estaba asustada porque los demonios les echaban con tierra y les tiraban piedras. La gente escapó al ver que no les dejaban velar el cuerpo esa noche. Lo dejaron así al muerto.

Al día siguiente dice que no tenía esta parte [señala gran parte del costado de la cabeza, cráneo y encéfalo]. "Solo estito" [señala con la mano como un palmo del cuello y parte del occipital] que aún le quedaba al muerto. "Dicen que sin cabeza estaba. No había su cabeza.

Si hemos reproducido largamente esta parte de la entrevista ha sido para dar una imagen clara de todo el horror que está aquí contenido. El narrador fue verdaderamente minucioso al dar detalles espeluznantes y vívidos del pedazo de cabeza y cuello que aún le quedaba al cadáver, luego del banquete de los demonios. Y también hemos reproducido largo porque aquí queda muy claro cómo el brujo y su cadáver "pertenecen" a los demonios.

Esta idea está reiterada en diversas entrevistas, algunas de las cuales reproducimos con brevedad:

Por eso el brujo vive en protección del diablo. El Dios ya no les castiga a ellos, tampoco verán su cara de Dios. Así es [...].

Hablando de eso [a dónde se van los brujos al morir] creo que ellos [los brujos] no van al cielo, sino se quedan en el infierno. Como además trabajan para el diablo, convidando los humanos a sus amos, si no cumplen a ellos mismos, se los come. Así dicen. Cuando se mueren, dicen que se van al barranco, a los lugares más feos que hay. Creo que ya no son humanos sino ya son parte del diablo.

Páginas atrás hemos afirmado que los relatos de brujería respondían a una necesidad profunda de la gente. Decíamos: De alguna manera los relatos de brujería parecen basarse en una necesidad cultural y espiritual. Debemos agregar que también ocurre con los "hechos de brujería", entendidos en el sentido amplio que hemos señalado. Pero ¿qué necesidad espiritual y cultural profunda llenan estas construcciones, que permita entender su producción permanente, remozada y reiterada? Pienso que la producción de relatos y hechos de brujería son "parte de la creación cultural andina": ellos constituyen "la creación cultural del horror". No estoy seguro de que una sociedad pueda existir sin crear alguna clase de horror. El tema es algo a discutir. Volveremos sobre él después de analizar el punto siguiente: la figura de los lik'ichiris, los "extractores de grasa humana".

\section{KHARISIRIS}

\section{Acercamientos}

La figura del lik'ichiri es bien conocida en Bolivia y en toda la región andina: es el popular "saca grasa", llamado también kharisiri (aym.) en Bolivia. En Perú, la figura es conocida como ñaq'aq (o nakaj) y pishtaku (quech.). Una de las primeras contribuciones a la descripción de este personaje, hoy ya clásica, es la que nos legara Rigoberto Paredes, hace ya más de sesenta años. En esas épocas, en Bolivia, para Paredes, el kharisiri estaba vinculado muy directamente a los frailes:

[Al fraile, el indígena] Le llama kharisiri, es decir, degollador, y cuenta de él que desde mediados de julio hasta mediados de agosto de cada año sale de su convento y recorre las estancias y rancherías del campo, en busca de grasa humana para confeccionar la crisma de los bautismos... apenas encuentra a un ser humano, lo halaga y le da un narcótico con el que lo adormece; y cuando está yerto, le hace una incisión en la barriga, hacia el lado derecho, por donde extrae toda la grasa... [La víctima] al despertar de su letargo no encuentra al funesto fraile pero siente un fuerte dolor en el vientre que le anuncia que algo grave ha ocurrido... por esta preocupación comienza a enflaquecer, hasta que... muere al poco tiempo del hecho (Paredes 1964: 31-31). 
Paredes (1964) documenta también testimonios coloniales, del siglo xvil, de la existencia de lo que él llama una "leyenda" semejante, con personajes llamados runap mickjuy. ${ }^{28}$

Los datos modernos de Rivière coinciden en mucho con lo narrado por Paredes:

\begin{abstract}
Se trata siempre de un personaje cuyo origen es extranjero al mundo indio, un cura o un monje, franciscano se precisa en varios casos. [...] Para cometer su fechoría se aprovecha del sueño de sus víctimas, haciéndolas dormir, hipnotizándolas con la mirada, la voz, el sonido de su campanilla o diversos ingredientes mágicos. Mediante una incisión, realizada en el costado (costado derecho se dice a menudo y no necesariamente en la garganta) con un objeto cortante (cuchillo, puñal y otros), extrae la grasa o el tejido adiposo de sus víctimas, operación tan discreta que no deja huellas y las víctimas ni la recuerdan. Los efectos son ineluctables: la víctima adelgaza y muere luego de algunos días o semanas. Se admite generalmente que el lik'ichiri es activo sobre todo en la noche, en los lugares desiertos y hacia el mes de agosto. La grasa extraída está destinada a diversos usos: confección de los santos óleos, de jabón, de velas, de ungüentos y pomadas de uso médico, fabricación de grasa para las máquinas, aleación de las campanas, etc. (Rivière 1991: 26).
\end{abstract}

Morote (1988) agrega una imagen muy concreta de la actuación típica de este personaje:

\begin{abstract}
Cuando en el ayllu ha caído derribada la tarde, cuando el silencio y la soledad conciertan lúgubremente en los caminos por hondonadas y peñascos; cuando el viento aúlla desesperadamente en los páramos, aparece el Nakaj provisto de sus polvos mágicos en espera del viajero solitario o del transeúnte que con retraso se recoge al bohío. Y sopla el polvo, paralizando toda acción defensiva de la víctima, que cae arrodillada o gateando a los pies del Nakaj. No hay súplicas, no hay llanto, ni siquiera una palabra de protesta o un grito de socorro. Calladamente, como si un nudo fuerte le apretara la garganta, como si un extraño poder le sujetara los miembros, queda, y se somete a la operación que le hace el malvado extrayéndole con maestría la grasa de los riñones, el unto, ${ }^{29}$ con un cuchillo o una hoja de arriero. Minutos después, cuando el Nakaj se ha ido, la víctima se sacude del sopor, tiene una extraña sensación de vacío, de que algo le falta. Como en sueños recuerda su encuentro con el Nakaj. Con un ligero temblor en el caminar, atolondrado, llega a su casa, directamente a la cama. Horas después un dolor de vientre se apodera de él, y ante la angustia de los suyos, fallece, luego de haber orinado un poco de sangre. Pero otras veces se extingue paulatinamente; no le duele el vientre, solo, sí, tiene desgano, pereza. Una palidez de cera baña más y más diariamente sus flácidas carnes. Y una tarde de esas, enteco, a pesar de la curación de brujos y paccos, ${ }^{30}$ queda yerto definitivamente (Morote 1988: 176).
\end{abstract}

Rivière 1991: 27, relaciona esta grasa con el alma: "el lik 'ichiri extrae la grasa -rara vez la sangre- del cuerpo de sus víctimas. En los Andes este producto, como la sangre [wila, en aymara] es asimilado con la fuerza de la persona y más particularmente con su 'alma' [ajayu], se dice que el lik'ichiri 'roba el corazón o el alma de su víctima"” (Rivière, 1991: 27).

Podríamos extendernos largamente sobre los significados fundamentales de las diversas clases de "alma" (cuatro o cinco) que conciben los indígenas andinos, de las que el ajayu (el jach'a ajayu, aym.) es la principal. Pero no es necesaria tal digresión para entender cuán aterradora o existencialmente aniquiladora puede ser la pérdida del "ser", tanto para un indígena andino como para nosotros, o como para cualquier hombre de cualquier otra latitud o cultura. Ciertamente, no es de la muerte de lo que estamos hablando, sino de la angustia de la aniquilación del ser. Tanto peor si consideramos que la religión andina, como muchas otras, concibe la continuidad de la vida $-\mathrm{y}$ por tanto del ser- más allá de la muerte. "Perder el ser" definitiva y absolutamente, debe ser una disolución de sî mismo inconcebible, insoportable e imposible de formular.

Estamos así sugiriendo que con el lik'ichiri la construcción cultural andina del horror parece adquirir una dimensión existencial inusitada, y ya no solamente mítica. Solo una concepción así permitiría entender la reacción tan profunda de espanto que él produce. Y sin embargo, ello no es siempre así. Y el personaje parece seguir sujeto a una lógica intrínseca, y a una dinámica sociocultural que estamos todavía muy lejos de visualizar.

\title{
LA REPRESENTACIÓN DEL OTRO Y LA MODERNIZACIÓN
}

Por el hecho de ser originalmente el kharisiri la representación de un extranjero, inspirada en la figura de los monjes bethelemitas (fines del siglo xvII), la mayoría de los estudiosos modernos sobre el tema proponen que este personaje es, definitivamente, una representación del "otro" no indígena, foráneo y enemigo. Es, nuevamente, Rivière (1991) el que con más precisión trata este aspecto del tema:

El lik'ichiri ocupa un lugar particular en la cosmovisión de los habitantes de los Andes. Por los rasgos que le son atribuidos (orígenes históricos y étnicos, apariencias y comportamientos), es una representación del forastero, del "blanco", del mestizo o, más generalmente, de este "otro" -llamado q'ara en aymara- quien no es reconocido como miembro del grupo, porque no se somete -o ya no- a las normas y prácticas colectivas, constituyendo así 
una amenaza permanente para su identidad. A diferencia de los otros personajes míticos, no es ambivalente y es siempre representado por rasgos exclusivamente negativos [...] Finalmente, porque escapa al dominio de los hombres, ninguna relación de reciprocidad o de "negociación” puede ser establecida con él" (Rivière 1991: 27).

Wachtel (1992: 113) reafirma esta concepción del "otro", del ajeno al grupo, que representa el kharisiri: "Si le kharisiri incarne, par définition, l'autre assimilé au mal radical (mais toujours bumain), on comprend qu'il puisse combiner une continuité pluriséculaire et des formes multiples, changeantes au gré des circonstances locales et de conjonctures historiques". Sin embargo, la expresión de "siempre humano", que utiliza Wachtel en relación con el kharisiri se verá negada, hacia el final de este trabajo.

Desde que el lik'ichiri apareció a fines del siglo XVII (es decir, desde que tenemos datos de su existencia) hasta hoy día, mucho ha cambiado en sus hábitos, modus operandi, parafernalia y atuendos. Ya no usa la saya tosca de antaño, ni el cordel grueso terciado en bandolera: hoy puede usar el traje de un médico, de un ingeniero, o incluso de un terrorista. Ya no usa la campanilla de sonido escalofriante en las callejuelas oscuras del pueblo para extraer la grasa, y ya no usa el cuchillo afilado o el punzón de un arriero, sino -en algunos relatos actuales- alguna clase de maquinilla moderna e, incluso, electrónica. Otros cambios son profundamente sugestivos. Si la figura del kharisiri es efectivamente la representación de "el otro, blanco, dominante y enemigo", ello hoy día ha perdido la rigurosidad anterior y puede aplicarse, incluso, a gente del mismo ayllu:

En noviembre de 1978, [en el pueblo de Maraya, nombre ficticio, en el departamento de Oruro] las autoridades tradicionales de este pueblo de origen Uru, detienen a cuatro comunarios originarios de los diferentes ayllu de la comunidad. Estos, que al parecer pertenecen al grupo de catequistas, son acusados de haber provocado la muerte de varias personas después de haberles extraído sangre, la cual habría sido vendida a extranjeros. Se dice que la sangre fue extraída con un "aparatito", versión que encontramos también en otros lugares. Es posible que este instrumento sea un sustituto de la campanilla, en las versiones más clásicas (Rivière 1991: 32).

Es decir, los kharisiris aquí no son representaciones del otro, sino son directamente indígenas, miembros de los distintos ayllus originarios, pero su pertenencia a una secta religiosa no compartida por todos es, al parecer, considerada como un elemento perturbador, extraño. Estos cuatro catequistas estaban ligados a expresiones y actividades de la sociedad moderna dominante.

Otro caso: en 1983, en Orinoca (también departamento de Oruro, cerca del lago Poopó), un kharisiri es ejecutado, su cuerpo es quemado, se le niega la sepultura y sus cenizas son esparcidas a los cuatro vientos. Esta persona tampoco era un extranjero: pertenecía a la comunidad indígena, pero se había apartado de ella:

Los comunarios lo acusan de haberse convertido a una secta evangelista y, siendo considerado como un líder potencial, de no querer participar ya en los cargos políticos rituales obligatorios. Se lo acusa de haber hecho un pacto con el demonio, quien le habría permitido enriquecerse lo suficiente como para comprar una camioneta utilizada con fines personales [a diferencia de los propietarios de camiones que con su vehículo "prestan servicios a la comunidad" y no son fastidiados]. [...] El juez de la comunidad, bajo la presión de los campesinos exacerbados, ordena su detención. M. A. es arrestado y atado a un poste colocado en la plaza. Se encontraron dólares en su casa saqueada, que probaba el condenable tráfico con el extranjero. Trata de escapar durante la noche, es capturado y golpeado hasta la muerte y no es enterrado. Este hecho es significativo. Temiendo que su poder, dañino, venga a alimentar las fuerzas del cosmos y continúe perturbando el mundo de los vivos, su cuerpo es quemado frente a su casa, sobre una hoguera alimentada con gavillas de $t$ 'ola ${ }^{31}$ traídas por todos los comunarios. Se dice que durante tres días y tres noches, salen de la hoguera llamas amarillentas color grasa hasta que el viento dispersa las cenizas "formando grandes torbellinos". De esta manera M. A. fue "expulsado" del mundo de los "hombres", material y simbólicamente; al negarle el derecho de ser enterrado, se le negaba también el derecho de ocupar un "espacio" y un "momento" en la pacha ${ }^{32}$ y finalmente en la "historia" de la comunidad (Riviere 1991: 33-34; Ramiro Molina, comunicación personal).

En 1978, cinco años antes de los sucesos de Orinoca, la aldea de Chipaya había sido estremecida también por una historia de kharisiris. Tres indígenas, miembros de la comunidad, en particular uno de ellos, fueron acusados igualmente de extraer y vender la grasa y la sangre de varias víctimas. Afortunadamente la llegada oportuna de algunos soldados de un destacamento cercano impidió que se consumara el ajusticiamiento y permitió la salvación de los acusados. Como se ve, también estos kharisiris eran indígenas (a diferencia de los relatos sobre brujos, este caso como otros mencionados en relación con kharisiris, se encuentran seriamente documentados).

Hablando de los cambios en la figura del lik'ichiri, Wachtel (1992) sugiere una hipótesis interesante: "L'exemple d'Orinoca (et de Chipaya) illustre une autre évolution non moins remarquable, qui correspond à une intériorisation en quelque sorte de l'altérité, puisque le kharisiri, certes lié au vastes réseaux du monde extérieur, est issu en l'occurrence du milieu indigène. Symptôme certainment d'une crise profonde: l'intrusion de la modernité au coeur des communautés andines menace jusqu'au fondements de leur identité" (Wachtel 1992: 114). 
Con estos cambios, los lik'ichiris siguen apareciendo de vez en cuando y provocando un profundo terror en la gente. Y resulta claro que interpretaciones del orden de que el lik'ichiri "es una representación del otro", si bien no carecen de fundamento, no bastan tampoco para explicar un fenómeno cuyos mecanismos profundos deberían ser materia de un estudio específico que permita acercarse a una comprensión mejor. De alguna manera estas reacciones indígenas ante los kharisiris me sugieren las actitudes, los sentimientos, los comportamientos, de las pequeñas sociedades y aldeas medievales europeas, que veían acercarse con pavor la llegada de las epidemias -cólera, peste bubónica, tifus exantemático- ante las cuales estaban por completo inermes. Lo que hay aquí es el sentimiento del peligro de estar ante una situación límite que amenaza desencadenar potencias incontrolables.

Rivière (1991), en las líneas que siguen, hace algunas sugerencias muy interesantes en relación con los movimientos relacionados con los lik'ichiris de comienzos de los años 80, en las regiones de Oruro y Potosí:

En primer lugar, es notorio que los movimientos se hayan desarrollado en momentos de "crisis": crisis económica, penurias, epidemias, mortalidad creciente para los años 1982-1983, desestructuración comunitaria, lucha interna entre "tradicionalistas" e iglesias o sectas, que desde hace algunos decenios se entregan a una lucha encarnizada en Maraya. Queda por hacer una antropología de la "crisis" y la desgracia en los Andes (un primer intento fue propuesto por Harris, O., 1987), pero numerosas fuentes concuerdan en considerarla como consecuencia de una "culpa", de una falta colectiva. En la región considerada aquí, la desgracia colectiva -que se manifiesta en forma de sequías o de inundaciones-, de epidemias o de epizotias, es interpretada como la consecuencia de una perturbación de las fuerzas del cosmos, de una ruptura o de un debilitamiento de los lazos que unen a los hombres con los dioses (Rivière 1991: 36 ).

Como antes con la "representación del otro", la situación de crisis, las epidemias, las enfermedades, las sequías, tampoco contribuyen mucho a aclararnos la consistencia mítica del kharisiri, ni a explicarnos los procesos hondos del pensamiento indígena ante él. Pero sí nos permiten comprender cuán frágil es la vida indígena, cuán desvalida es y cuán dispuesta puede estar la gente a concebir entidades de la maldad y de la acción contra el ser, ante las cuales no tiene ninguna protección.

\section{Los juegos del humor. La sexualidad del kharisiri}

A pesar del predominio de los componentes negativos y aterradores del kharisiri, los indígenas andinos hacen entrar de todos modos al personaje en sus juegos que expresan lo que alguna vez he llamado la "vacilación epistémica del humor". Un largo argumento, que no podríamos repetir en detalle aquí, nos muestra que en muchos rituales andinos la actitud de los participantes contiene una determinada dosis de humor, manifestada en risas, chistes, payasadas, decires y haceres jocosos, que nos hacen sentir como si estuviesen al filo, muchas veces, de la creencia/no creencia en las deidades o entidades míticas. Por ejemplo, para la "Despedida de las Almas", del 2 de noviembre, en la comunidad de Rakhay Pampa, al final del día, después de llantos y adioses, un campesino se disfraza de "alma" con una sábana blanca, y amedrenta a los participantes, sobre todo mujeres y niños, haciendo como que se los lleva con él a la tumba, lo cual ocasiona risas, huidas, alborotos. Por último, al alma le lanzan bostas de caballo, terrones, palos, para que se vaya y deje de molestar a los vivos. Podríamos multiplicar estos ejemplos. Aunque parezca increíble y resulte inusitado, también el lik'ichiri es un personaje que entra en los juegos de este tipo.

Así, Salazar-Soler (1991) relata unas representaciones teatrales humorísticas que hacen los chicos de una escuela, para Navidad, en Huancavélica (Perú). Cuenta que:

La segunda escena es aún más importante para nuestro propósito. Llevaba el título de "Juicio a los Abigeos". Al inicio de esta escena, había un grupo de campesinos que discutían, ellos representaban la asamblea comunal que iba a juzgar a los abigeos. Estos abigeos situados al extremo opuesto eran dos. Uno de ellos estuvo representado por un niño que llevaba un gorro blanco de lana de oveja, bigote y barba blanca postiza igualmente en lana de oveja, y llevaba unos anteojos de sol, el otro estuvo representado por una llama. Luego la asamblea comunal los hizo acercarse llamándolos "Pishtaku $u^{33}$ pene loco y su Hermana". Los acusaban de ser ladrones de ganado, pero también de matar runa ${ }^{34}$ para extraerles la grasa y finalmente de mantener relaciones sexuales entre ellos. La asamblea los condenó a muerte, debían ser decapitados y sus cabezas quemadas.

[ ...] ...en el relato sobre la representación teatral en la comunidad, se subraya el comportamiento sexual licencioso del Pishtaku. En el testimonio se le acusa de ser incestuoso: "disque se ha metido hasta con sus propias hermanas". En la representación teatral, la asamblea comunal llama a la persona que está siendo juzgada, con el nombre de "Pishtaku pene loco" (Salazar-Soler 1991: 19).

Debe recordarse que también los dioses de los cerros (mallkus, apus) ${ }^{35}$ tienen reputación de una sexualidad excesiva. Y también los brujos y, por supuesto, los diablos que, por lo demás, son los mismos dioses de los cerros (Martínez 1983). De manera que este rasgo no es exclusivo del kharisiri. Por lo general, esta sexualidad desbordante 
es indicativa de un poder genésico y creador igualmente desbordante, rasgo perfectamente aplicable a los dioses de los cerros, a la pacha mama, ${ }^{36}$ a los "tíos" de las minas, y seguramente a otras entidades míticas. No sería el caso de los brujos. Y en el caso específico del kharisiri que participa en la representación teatral, su sexualidad desbordante ("pene loco") va al lado del incesto y de toda una conducta antisocial de desorden y destructividad. Por lo demás, según se dice, el kharisiri puede ser hombre o mujer, pero no hemos encontrado ningún relato de kharisiris mujeres. Y del kharisiri varón se especifica que puede engendrar, pero un solo hijo hombre, destinado a sucederle en sus malas artes.

En cambio, la participación de los estos lik'ichiris en los juegos del humor y la sacralidad, resulta coherente con el marco epistémico general de la cultura andina, donde las vacilaciones entre el creer y el no creer nos parecen una constante y lo hemos considerado un hecho consistencial mismo de la cultura. Debo confesar, sin embargo, que ese rasgo me sigue pareciendo sorprendente e inusitado en relación con los lik'ichiris, debido con seguridad al peso definitivo que desde un comienzo he asignado a los caracteres negativos y aterradores de esta figura. Pero es justamente esta posibilidad de burla la que hace sospechar que tampoco aquí, en lo aterrador de los likichiris, estamos en el reino de lo absoluto.

\section{Los casos de lik'ichiris y la comunidad (el conflicto comunitario)}

Se sabe que en la mayoría de los casos de intervención de comunarios en historias de lik'ichiris, es la comunidad entera, o parte importante de ella, la que asume la responsabilidad por la ejecución del ajusticiamiento, con notoria unanimidad. En el caso señalado más arriba de Orinoca: "Los policías enviados por la Prefectura del Departamento no pudieron llevar a cabo su investigación; chocaron con el mutismo de la población y debieron regresar a Oruro sin haber podido identificar a "los culpables". Este extraño "asunto" - cosa de indios, al decir de algunos- que escapaba a los delitos normalmente tratados por la justicia oficial, fue "archivado provisionalmente" (Rivière 1991: 34).

No es el único ejemplo. Y, sin embargo, de una manera u otra, me asiste la impresión de que siempre se vislumbra, aunque confusa, la participación protagónica de algunos miembros de la comunidad que parecen gestar e impulsar los acontecimientos, ya sea lanzando la acusación de lik'ichiris contra las víctimas, ya sea estimulando sentimientos negativos en la gente, ya sea organizando acciones de castigo. Si las consideramos en sí mismas, estas intervenciones personales parecieran desvanecer el carácter "mítico" de la actuación de la comunidad para dejarnos frente a acciones manipuladas que habrían perdido todo el carácter de pensamientos, sentimientos, creencias que se dan en el seno de otra cultura: este tipo de acciones no necesitaría de ninguna interpretación antropológica ni una consideración de que estamos frente a un hecho de justicia consuetudinaria.

Sin perjuicio de que aparezcan intervenciones como las que he señalado, creo que las incitaciones protagónicas al castigo, no pueden ser tomadas en cuenta como acciones con motivación personal. Si hay agentes manipuladores que juegan un papel importante en desatar acusaciones y castigos contra presuntos lik'ichiris, ellos son también indígenas y miembros de la misma comunidad, y partícipes de la misma cultura. Y de todas maneras, es la reacción de toda esa gente junta lo que nos interesa entender. ¿Qué, pues, explica el terror que levanta el lik'ichiri? ¿Cómo entender que toda una comunidad -o parte mayoritaria de ella- crea en las acusaciones lanzadas contra otros miembros de la comunidad y tome parte en el ajusticiamiento?

Creo que la única explicación verdaderamente válida es una que me ha sido dada por la lectura de un artículo de Jan Szemiñski (1989), donde el autor explica por qué se mató a españoles en las sublevaciones indígenas de 1780-1784 (las de los Amaru y los Katari, en Perú y Bolivia), no bastando para entenderlo los obvios motivos de venganza, de ira y dolor acumulados en los indígenas por los ya 300 años de expoliación, pillaje, maltrato y opresión de los españoles.

No podremos repetir aquí todos los argumentos y datos del autor, pero en lo esencial se trata de que los indígenas sublevados y sus dirigentes se sentían perfectamente justificados o autorizados matando españoles (en particular autoridades, corregidores, hombres ricos, comerciantes, soldados, incluso caciques e indios españolizados), porque todos fueron considerados como no humanos, demonios, por tanto herejes, apóstatas y no cristianos. Como dice el autor, "Los estados demoníaco y de bestialidad son perfectamente compatibles: ambos son no humanos" (Szemiñski 1989: 26). Más adelante Szemiñski comenta, refiriéndose a la interpretación que hace otro autor de la muerte de un cacique comparándola con una wilancha. ${ }^{37}$ "Si comparamos una wilancha practicada con una llama con los casos de wilancha en españoles, la única diferencia está en que estos últimos no fueron sepultados. La prohibición de sepultar españoles fue dada para asegurarse de que los cadáveres de 
los españoles muertos no se convirtieran en mallki. Un mallki es una planta de nueva vida que ha renacido gracias a la Pacha mama" (Szemiñski 1989: 26-27).

Compárese la conducta hacia los españoles, documentada en el texto de Szemiñski, con la conducta de los que mataron al presunto lik'ichiri de Orinoca. Ellos tampoco quisieron sepultar el cadáver y en su lugar, lo quemaron. Pero las palabras que siguen son aún más aclaratorias de esta relación entre matanzas a españoles en las rebeliones y "sacrificios" a lik'ichiris:

De los ejemplos citados se puede asumir que todo caso de cadáver los dioses o a Dios, y que los rebeldes trataban de evitar su renacimiento. Al mismo tiempo confirma la condición de bestias o demonios indeseables que tenían los españoles. Considero que es posible identificar el tipo de demonios que eran los españoles. Según creencias panandinas, existe una clase de gente que es humana y no humana, a la que en castellano se denomina "degollador". En quechua se lo conoce con el nombre de "pishtakuq" [...]. Según la mitología andina, los "nakaq" son identificados con los blancos ${ }^{38}$ (Szemiñski 1989: 27).

Estas líneas me parecen totalmente pertinentes al caso actual. Lo único que cabe pensar, pues, es que en los indígenas andinos está completamente viva la creencia en la condición humana y a la vez no humana y demoníaca del kharisiri. Y si tomamos en cuenta las observaciones de Rivière (1991) de que la mayoría de estos casos de lik'ichiris se han producido en condiciones de crisis económica, de hambruna, sequía, muerte de animales, enfermedades de niños, en fin, toda una situación de ruptura mortal del equilibrio entre los hombres y los dioses (o Dios), y si tomamos en cuenta también el debilitamiento de la fortaleza identitaria que representan las luchas de sectas (Wachtel) y los ataques de estas contra la religión tradicional, a nadie le extrañará que la muerte de un kharisiri tenga todo el sentido de un sacrificio a las deidades destinado a restablecer el equilibrio con ellas.

\section{ALGUNAS CONSIDERACIONES TEÓRICAS}

Como lo dije anteriormente, al iniciar mi investigación sobre conflictos sobrenaturales en las comunidades indígenas decidí centrar primero mi atención en la brujería andina. Pero este término precisaba de una mayor delimitación. En muchas ocasiones se identifican magia y brujería, y en la práctica no siempre es fácil distinguir un mago de un brujo, si es que pueden establecerse fronteras precisas. Pero al interior de este vasto campo existen prácticas mágicas conocidas como "blancas o buenas" ("dulces", en términos andinos, misk'i misa, la llaman los oficiantes) que no están destinadas a causar daño y que difícilmente provocan conflictos en el seno de las comunidades.

Lo que constituía, en realidad, mi tema al interior de la brujería estaba predeterminado por la noción de conflicto. Por lo general, en la disciplina antropológica, lo que en general se entiende por brujería está marcado, justamente, por un efecto de "desastre". Favret-Saada (1991) define este que fue el objeto de nuestra investigación:

\footnotetext{
En su uso antropológico "brujería" designa antes que nada los efectos nefastos (accidente, muerte, infortunios diversos) de un rito o de una cualidad inherente al brujo. Para numerosas poblaciones, el brujo es un ser humano en apariencia semejante a los otros pero secretamente dotado de poderes extrahumanos (a veces sin saberlo él mismo) y responsable de desgracias que golpean a sus próximos. Al ocultarse la naturaleza y la actividad de los brujos a la percepción ordinaria, sus víctimas (los embrujados) están obligados a recurrir a la práctica adivinatoria de un contrabrujo: este está provisto de técnicas y/o de un don de videncia extraordinarios que le permiten desenmascarar al culpable e iniciar los medios de reducir el infortunio (Favret-Saadat 1991: 670).
}

Hace algunas décadas, los etnólogos gastaban considerable cantidad de esfuerzo en disquisiciones terminológicas y problemas de definición: magia preventiva o magia activa, magia blanca o magia negra, magia imitativa o magia contaminante (Frazer 1944: 33), y otras clasificaciones. Algunos continúan todavía con estas discusiones, especialmente respecto de la magia/brujería andina. Pero todas estas definiciones están en función de concepciones convencionales y ya superada en la disciplina antropológica, que pretendían establecer fronteras precisas entre magia y religión. Alleau y Bastide (2015) plantearon este problema con gran precisión:

M. Mauss, dans son Manuel d'ethnographie, recommandait aux jeunes ethnographes spécialistes des phénomènes religieux la méthode philologique: "Seul importe, ajoutait, le point de vue indigène. A la limite, l'idéal serait de transforme les indigènes non pas en informateurs, mais en auteurs". Et, cependant, malgré cette recommendation importante, on a vu que toute l'anthropologie religeuse essaie de dégager une catégorie universelle de la magie par opposition à la religion, qui serait en quelque sorte sous-jacente aux faits, et que, de plus cette catégorie de la magie est plus saisie dans son point d'arrivé (c'est à dire notre définition à nous) que dans son point de départ (l'inextricable confusion du magique et du religieux dans les sociétés traditionnelles); d'où un risque d'etbnocentrisme. Il semble bien que l'on se rend compte aujourd'bui de ce danger; les catégories linguistiques occidentales (religion, magie, sorcellerie) ne recouvrent pas forcément les categories des autres populations [...] (Alleau \& Bastide 2015). 
Pero la decisión que he señalado más atrás de centrarme en la brujería contraía también una serie larga de constricciones. Una de ellas, es que de hecho las fuentes de información de esta clase de magia andina son enormemente limitadas: como se ha dicho ya; el auténtico brujo actúa en el secreto y lo que se sabe de sus prácticas es verdaderamente mínimo. La investigación de campo -que además fue en este caso obligadamente breve- si es que logra vencer los hermetismos de la gente, no llena los vacíos y se conjunciona con la escasez general de información etnográfica escrita. De manera que nuestro enfoque ha tenido que ser obligadamente parco en los detalles y exterior en su calidad. En circunstancias de que, en esta clase de temas, el anhelo del investigador es lograr una intimidad personal satisfactoria con la persona que sabe, y una percepción de la interioridad de su pensamiento que permitan abrir las puertas de la certeza y seguridad de la información.

La selección de la brujería (maléfica) como una de las principales causas de conflictos sobre naturales y el tiempo limitado dado a esta investigación, me ha impedido tratar las relaciones entre la brujería y las otras clases de magia/brujería andina. La brujería maléfica no puede ser entendida como una especialidad aislada de la magia en los Andes; las actuaciones de un brujo maligno no pueden entenderse sin referencia a los desempeños, técnicas e ideología de las muchas otras clases de yachaj, yatiris, aysiris y ch'amakanis que hemos ido nombrando a lo largo de este trabajo. Sospecho que todos ellos y sus ciencias respectivas constituyen un sistema estructurado, y no se puede entender un componente sin tomar en consideración los otros. Dentro de este sistema hay un espacio continuo de fuerzas sobrenaturales invocadas y metodologías de acercamiento a ellas, que tienen mucho en común, aunque sea para obtener diferentes resultados. Pero no es a este conjunto de personajes y procedimientos mágicos que hemos enfocado nuestra atención: hemos aislado, dentro de ellos, solamente lo relacionado con lo maléfico. Estudios posteriores deberían devolverlo a las concepciones generales del mundo que permiten la manipulación de lo natural por medio de leyes no causales. Como bien decía Mauss (1979), el hecho mágico (y dentro de él, la brujería) debería ser abordado con un enfoque totalizante sobre la sociedad en la que se lo estudia: la magia tiene un carácter pluridimensional y un carácter de fenómeno social total. Estamos conscientes de esa necesidad de instalar los hechos de brujería en un contexto social y cultural al cual ellos pertenecen y del cual no pueden ser aislados, pero esta tarea es una de largo alcance, que no podía ser abordada en una primera aproximación. En este trabajo, como se desprende de los análisis realizados, se ha dejado totalmente de lado la perspectiva teórica del evolucionismo, muy vigente todavía en nuestro país, que opone la magia a la racionalidad, como si fuese un hecho anterior, primitivo, por así decirlo, en relación con la razón:

La tesis de una progresiva diferenciación entre ciencia, religión y magia ha sido propuesta por Frazer (1900). A partir del siglo xvi, el saber empíricamente verificable se aparta del conocimiento dogmático que se sustrae a priori a toda verificación experimental como la fe religiosa, o se funda sobre falsas premisas como la magia. Una tal ideología intelectualista y evolucionista opone la magia y la religión a la racionalidad o a la ciencia, asociando esta oposición a un conflicto entre pensamiento arcaico y pensamiento moderno. Es este justamente uno de los fundamentos ideológicos de quienes hacen del anti-indigenismo una profesión de fe. La tesis que sustentan es una tesis intelectualista, que "reduce la magia a una ciencia bastarda atada a una causalidad falsa, por insuficiencia experimental" (Devisch 1991: 431-433).

Ciertamente me hubiera gustado incorporar de manera más sistemática una visión estructuralista levistraussiana al análisis de los materiales. Aunque ya bastante antiguo, el artículo de Lévi-Strauss El hechicero y su magia (1958) resulta aún muy sugerente. Pero nuestra búsqueda estaba demasiado dirigida a los casos de brujería que pudieran dar pie a conflictos de origen sobrenatural con intervención de la comunidad, y estos trabajos de Lévi-Strauss están más orientados a intervenciones curativas. De todos modos, algo de ese espíritu levistraussiano se conserva en el trabajo al considerar, en particular, el material de brujería recolectado por nosotros, como afirmación del pensamiento mágico y desarrollo de la creación cultural mítica andina.

En cambio el enfoque del material de brujería está muy cerca del punto de vista y las técnicas semióticas de análisis. Tuve que hacer verdaderos esfuerzos por no dejarme llevar por estas aproximaciones (que, por lo demás, nunca se han hecho sobre material andino). Los relatos de brujería, como se lo demuestra mediante sus "motivos" ya hechos tomados de una larga tradición narrativa no específica de la brujería, se presentan como verdaderas construcciones de significación: resultaba evidente la posibilidad de extraer, con cierta facilidad, los programas narrativos de cada relato y/o acción. Pero un tratamiento más a fondo sobre los sentidos que hace aparecer cada relato, considerado como un texto, hubiese desviado el trabajo hacia las significaciones, hacia el pensamiento contenido en ellos: debido al corto tiempo de que disponíamos, este análisis semiótico no pudo ser abordado con profundidad. 
El enfoque que se desarrolla en relación con los "hechos de brujería", que se expresan en tanto una práctica concreta como en las relaciones conflictivas interpersonales de los miembros de una comunidad, es un resultado de nuestra reflexión a partir de los materiales disponibles. Este resultado estaría muy cerca del pensamiento de la Escuela de Manchester, de orientación funcionalista, para la cual la magia se inscribe en el campo general del "conflicto social". Esta cercanía, sin embargo, no es resultado de un apoyo teórico en esta escuela, sino una presentación que los propios hechos de brujería hicieron ante mí mismo.

\section{ALGUNAS ACLARACIONES METODOLÓGICAS}

A menudo, en los análisis, hemos tomado en cuenta para la mejor comprensión del fenómeno hechos ocurridos hace doscientos años como es el caso de la comparación entre las muertes de españoles durante las grandes rebeliones indígenas con los castigos a lik'ichiris ocurridos en épocas actuales. Esta puesta en relación implica que se postula una continuidad de algunos aspectos de las culturas andinas, a pesar de las grandes transformaciones de la Colonia, de la República y de la modernización actual de las comunidades indígenas. No se trata, naturalmente, de negar la no existencia de profundos procesos de cambio, pero sino de percibir, a pesar de ellos, la fuerte permanencia de visiones del mundo, que, en nuestro caso específico, están en la base de pensamientos y acciones colectivas. El pasado, en algunos casos, permite entender el presente. Por otra parte, hemos subrayado los aspectos cambiantes del kharisiri actual: ha dejado de ser simplemente la visión del "otro", extranjero, blanco, para internalizar lo extraño y superponerlo a miembros de la propia comunidad, vistos como una amenaza por romper la costumbre tradicional (enriquecerse demasiado, adoptar una religión distinta). De este modo la historia viene en apoyo de la comprensión de los hechos actuales, al permitirnos enfrentar similitudes y diferencias

Los materiales para acercarse al tema fueron de dos naturalezas diferentes: la primera tarea fue confeccionar una bibliografía adecuada al tema y luego el trabajo teórico con ella, para definir una aproximación concreta de este trabajo en el tiempo otorgado a la investigación. La otra índole de materiales a analizar la constituyeron las numerosas entrevistas realizadas en terreno.

Este material etnográfico fue obtenido en comunidades del departamento de Chuquisaca, mediante grabaciones magnetofónicas de conversaciones con personas que, en su gran mayoría, eran ya amigos o conocidos, lo que facilitó la información sobre estos temas que no comparten fácilmente. Ya se ha dicho que el principal problema que enfrentaba nuestra investigación era la carencia de material etnográfico fidedigno y actual. Estas entrevistas siguieron las pautas de un cuestionario preelaborado que fue manejado, simultáneamente a mí mismo, por un ayudante de campo.

De los textos obtenidos fueron surgiendo datos para guiar el análisis, muchas veces contrastando con otros conocimientos de la vida en las comunidades, por ejemplo, los escasos hechos de castigo a los brujos en la vida normal, en relación con la profusión de ellos en la ficción del relato. Igualmente, nuestra experiencia mucho más directa y participativa con yatiris que con brujos, nos permitió, sin embargo, establecer coincidencias y sostener la hipótesis de que se trata de un mismo universo semántico de creencia y etnoclasificaciones, operado, sin embargo, con distintas finalidades.

Debido al carácter secreto de las manipulaciones de la brujería, no fue posible una participación y observación directa de los hechos, salvo el caso que narro en el texto.

Toda una metodología de apoyo en lo "concreto": apoyo en la comprensión del "set" de objetos y sustancias utilizado y el estudio de sus nombres y el significado de ellos; apoyo en los pasos del ritual de brujería mismo, palabras pronunciadas, hechos y gestos, horas exactas, épocas del año, etc., no ha podido ser utilizada por las restricciones de tiempo. Ella hubiese sido extraordinariamente importante desde el punto de vista de comprensión más profunda de los hechos, pero creemos que no hubiese alterado las conclusiones con relación a que hay aspectos míticos actuando en la base del comportamiento hacia los ajusticiamientos, sea de brujos, sea de kharisiris.

\section{CONCLUSIONES}

Si el objetivo principal de esta investigación era ver, o por lo menos conocer más, cómo opera la justicia comunitaria en aquellos conflictos de carácter sobrenatural, de manera general este objetivo no se ha logrado. Recuérdese cómo 
en la investigación relacionada con la brujería, tanto en el caso de los relatos de brujería como en los hechos de brujería, llegábamos a la conclusión de que carecíamos de evidencia suficiente para afirmar o para negar que en las comunidades andinas se produjeran con frecuencia conflictos de esta naturaleza: conflictos de la comunidad -O de un grupo de ella- con un brujo que hubiera hecho daño a alguien, y que obligaba a la comunidad a intervenir castigando, de una manera u otra al brujo. Adviértase bien que no estamos afirmando o negando la producción de estas situaciones: solo indicamos que no tenemos evidencia suficiente, y esto por falta de información etnográfica en cantidad y calidad necesaria. También concluíamos lo mismo respecto de los castigos infligidos a los brujos: teníamos la impresión de que los ajusticiamientos extremos (muerte por fuego, colgamiento, etc.) se producen muy pocas veces en la realidad, y no parecen ser parte de la tradición andina. Como antes, tampoco aquí hay documentación suficiente.

En segundo lugar, ligeramente diferente es la situación con los kharisiris. Como se dijo, hay constancia documentada de casos de ajusticiamiento de personas acusadas de ser kharisiris. Lo que falta en estos casos es la información bien detallada y precisa, especialmente de las argumentaciones y razonamientos del proceso mismo de enjuiciamiento (aunque aquí no cabe de ninguna manera este término) y de la ejecución de la sentencia. Por lo demás, difícilmente un testigo externo y preparado en la observación rigurosa de los hechos hubiese sido admitido, ni en las deliberaciones ni en el ajusticiamiento mismo. La diferencia está no solo en la naturaleza misma de los casos de brujos y lik'ichiris, sino en que hemos logrado darles a estos casos, y al personaje, una explicación que nos parece satisfactoria, acorde con la cosmovisión indígena, con la historia y con la coyuntura socioeconómica real, y con las modalidades clasificatorias del pensamiento mítico tradicional. Aunque no hayamos visto operar la justicia comunitaria, entendemos algo mejor que antes las lógicas indígenas que presiden estos acontecimientos.

Una tercera conclusión: es que existe una "creación cultural andina del horror", como en toda cultura. La figura del brujo, como aquella del lik'ichiri, son parte de esta creación. A la figura del lik'ichiri se le da, por el momento, una función a cumplir mucho más pesada que la del brujo y, al parecer, en directa relación con el equilibrio necesario para la sobrevivencia de una comunidad, especialmente en épocas de crisis. Sin embargo, un conocimiento más profundo sobre el papel social que juega la figura del brujo permitiría, tal vez, entender la manera como ella es utilizada en la conservación y supervivencia del grupo, en una comunidad o en el espacio mayor de un ayllu.

Si hay una conclusión que se impone es la de realizar una segunda fase de investigación, para tratar de resolver los problemas que ahora quedaron inconclusos (por ejemplo, las prácticas reales de brujería), y para conocer en mayor profundidad tanto la problemática misma de la justicia consuetudinaria como los materiales y personas que involucra. Nos parece que una comprensión de qué es y cómo funciona una "justicia comunitaria” en relación con temas de carácter mágico, sobrepasa el tratamiento solo de conflictos extremos (ajusticiamientos de brujos y muertes de kharisiris) y debe abarcar la participación, los desempeños y las funciones de otras clases de especialistas religiosos. En rigor, esta primera investigación que hemos realizado ha sido muy valiosa, pero es solo una toma de contacto inicial con los problemas de personajes y de problemáticas teóricas aquí implicadas.

\section{NOTAS}

${ }^{1}$ En la edición original existió un segundo tomo que contenía solamente los textos (en español) de las entrevistas hechas en las comunidades, y que sirvieronn de fundamento a las consideraciones analíticas hechas en el presente volumen. Desgraciadamente aún no podemos tener acceso a ese volumen. En esta edición se respetan los criterios ortográficos adoptados originalmente por el autor según los cuales en las localidades rurales que aparecen en los mapas, se conserva su ortografía castellana. En cambio, topónimos que nombran pequeños lugares al interior de las comunidades, están transcritos con ortografía quechua. Las referencias bibliográficas del documento original fueron cotejadas y actualizadas, razón por la cual los lectores encontrarán fechas de edición posteriores a la redacción de este manuscrito.

${ }^{2}$ En este caso como en otros en que el narrador cita, concretamente, a personas existentes, estamos cambiando el nombre por otro supuesto.

${ }^{3}$ Llamero: la gran mayoría de los primeros relatos consignados en este trabajo fueron recogidos en la región jalq'a, área cultural que se extiende al este y noroeste de la ciudad de Sucre. Los jalq'a designan con el nombre genérico de "llamero" a sus vecinos que habitan las tierras más altas en el norte del Departamento de Potosí (pertenecientes, por lo general, a los grandes ayllus Macha, Tinquipaya, Pocoata, etc.) que limitan el territorio jalq'a por el noroeste y que, supuestamente, son todos criadores de llamas.

${ }^{4} J a r a n a:$ en ciertas épocas del año, los llameros van con sus caravanas de llamas llevando productos de altura para intercambiar con los de valle y atraviesan la zona jalq'a descansando en lugares específicos llamados jarana.

${ }^{5}$ Q'aytu: hilo de lana hilado a mano.

${ }^{6}$ Yatiri: la designación es bien conocida en el territorio andino señalando a aquel que sabe comunicarse con fuerzas sobrenaturales para realizar peticiones a las deidades, curaciones o deshacer hechicerías. A diferencia del brujo, el yatiri es considerado como haciendo siempre un trabajo "para bien" en contraste con el "mal" que puede causar el brujo. Sin embargo, los límites entre uno y otro no son siempre bien precisos. 
${ }^{7}$ Aysiri: es casi un equivalente de yatiri, salvo que, en las regiones de Chuquisaca, parece tener poderes más amplios, como convocar la presencia de los mallkus (dioses tutelares que habitan en los cerros) en ceremonias donde ellos se presentan y hablan mediante diferentes voces que hace el aysiri.

${ }^{8}$ Mallkus y "virginas" son deidades tectónicas masculinas y femeninas.

9 Jampiri: equivalente, en cierto modo a yatiri, pero con más énfasis en la medicina mágica y herbolaria. En las localidades rurales que aparecen en los mapas estamos conservando su ortografía castellana. En cambio topónimos que nombran pequeños lugares al interior de las comunidades están transcritos con ortografía quechua.

${ }^{10}$ Wayq'u: quebrada, barranco.

${ }^{11}$ Ayllu: el término tiene diferentes niveles. Implica siempre a un grupo, puede ser un grupo pequeño de parentesco directo, una sección de una estructura mayor o un grupo de grandes dimensiones que tiene una organización y autoridades tradicionales comunes. En este caso, se trata del ayllu Isluga, un grupo de unas dos mil personas, organizado en mitades.

${ }^{12}$ Estancias son llamados los rancheríos que forman parte de un ayllu.

${ }^{13}$ No hemos encontrado aún traducción, posiblemente una planta local.

${ }^{14}$ Semilla amarillenta en forma de espiral que es utilizada para "dar la vuelta" (cambiar) una situación por su opuesta.

15 Chamak'ani: yatiri que opera con mesas negras, mesas para "hacer contra" o dedicadas a las deidades subterráneas.

${ }^{16}$ Sahumerio con una hierba perfumada llamada q'owa.

${ }^{17}$ Tatay: tratamiento respetuoso hacia el padre como hacia cualquier hombre en general.

${ }_{18}$ Choqes: literalmente, oros. Posiblemente objetos metálicos brillantes pertenecientes a la parafernalia del brujo.

${ }^{19}$ Inkhuña: tejido pequeño para llevar o amarrar cosas varias y también para llevar hojas de coca.

${ }^{20}$ Chukisusus y Q'erinkha: pájaros del brujo.

${ }^{21}$ Chullperíos: lugares donde hay ruinas que se suponen pertenecieron a viviendas de los chullpas, una humanidad anterior.

22 T"ujlus: calaveras.

${ }^{23}$ Ch'allaron: verbalización del término quechua, ch'alla.

${ }^{24}$ Paqo: sacerdote nativo.

${ }^{25}$ Picharas: materiales varios con los que se unta a un enfermo, mientras se reza para que sane.

${ }^{26}$ Cb'allaku, de ch'alla, libación.

${ }^{27}$ Pukara: sitios sagrados generalmente en lo alto de los cerros con pequeñas construcciones de piedra.

${ }^{28}$ Ortografía del autor para la expresión quechua runa mikuj, el que come gente. El testimonio citado por Paredes pertenece al del Obispo Villagómez "Carta Pastoral de Exhortación e Instrucción contra las idolatrías de los indios del Arzobispado de Lima" 1649.

29 Untu: grasa, en quechua.

30 Paccos: en la ortografía del autor corresponde a paqo, ya citado.

${ }^{31}$ T'ola: arbusto leñoso.

32 Pacha: el tiempo espacio en la concepción andina. El mundo. El kharisiri es expulsado de este mundo

${ }^{33}$ Recordemos que phishtako es una de las maneras de llamar a los lik'ichiris, en quechua, en el Perú.

${ }^{34}$ Runa: persona (quechua).

${ }^{35}$ Ap us: otra denominación para los dioses tutelares de los cerros.

${ }^{36}$ Pacha mama: a pesar de que en los medios urbanos se la considera como una "madre tierra", es en verdad una deidad andrógina, con sus aspectos masculinos y femeninos, dadora de la fecundidad agrícola.

37 Willancha: rito aymara de ofrenda a los dioses tutelares en los que se sacrifica una llama.

${ }^{38}$ Szemiñski (1989: 27) se refiere a una interpretación de Jorge Hidalgo en "Amarus y cataris: Aspectos mesiánicos de la rebelión indígena de 1781 en Cusco, Chayanta, La Paz y Arica".

\section{REFERENCIAS}

AlleAu, R. \& R. BASTiDe, 2015. Magie. En Encyclopcedia Universalis http://www.universalis.fr/encyclopedie/magie/ [consultado 24-03-2015]. Devisch, E., 1991. Magie. En Dictionnaire de l'Ethnologie et l'Anthropologie, P. Bonte \& M. Izard, Eds., pp. 431-433. Paris: Presses universitaires de France.

Frazer, J.G., 1944. La rama dorada. México, D. F.: Fondo de Cultura Económica.

Favret-SaAdat, J., 1991. La sorcellerie. En Dictionnaire de l'Ethnologie et de l'Anthropologie, P. Bonte \& M. Izard, Eds., pp. 670-673. Paris: Presses universitaires de France.

Harris, O., 1987. De la fin du monde. Notes depuis le Nord-Potosí. Cahier des Amériques Latines 6: 93-117.

LÉvi-Strauss, C., 1958. El hechicero y su magia. En Antropología Estructural, pp. 183-203. Barcelona: Paidós.

MarTínez, G., 1973. Humory Sacralidad en el mundo autóctono andino. Iquique: Universidad de Chile.

Martínez, G., 1983. Los dioses de los cerros en los Andes. Journal de la Société des Américanistes 69: 85-115.

Mauss, M., 1979. Sociología y Antropología. Madrid: Tecnos.

Morote, E., 1988. Aldeas sumergidas. Cultura popular y sociedad en los Andes. Cusco: Centro de Estudios Rurales Andinos "Bartolomé de las Casas".

PAREDES, R., 1964. Mitos y superticiones y supervivencias populares de Bolivia. La Paz: Ediciones Isla.

RIVIÈRE, G., 1991. Lik'ichiri y kharisiri... A propósito de las representaciones del "otro" en la sociedad aymara. Bulletin de l'Ínstitut Français d'Etudes Andines 20 (1): 23-40.

Salazar-Soler, C., 1991. El Pishtaku entre campesinos y mineros de Huancavelica. Bulletin de l'Institut Français d'Etudes Andines 20 (1): 7-22. SZEmiÑski, J., 1989. El único español bueno es el español muerto: Maten a los españoles. En Pishtacos. De verdugos a sacaojos, Juan Ansión, Ed., pp. 19-60. Lima: Tarea.

TAYLOR, G., 1987. Ritos y tradiciones de Huarochirí en el siglo XVII. Lima: IEP.

Wachtel, N., 1992. Dieux et vampires. Retour a Chipaya. Paris: Editions Du Seuil. 
